\title{
Towards a Flood Vulnerability Assessment of Watershed Using Integration of Decision Making Trial and Evaluation Laboratory, Analytical Network Process, and Fuzzy Theories
}

Farzaneh Sajedi Hosseini

University of Tehran

Shahram Khalighi Sigaroodi ( $\square$ khalighi@ut.c.ir)

University of Tehran

Ali Salajegheh

University of Tehran

Alireza Moghaddamnia

University of Tehran

Bahram Choubin

AREEO: Agricultural Research Education and Extension Organization

\section{Research Article}

Keywords: Flood vulnerability, DEMATEL, Interdependency, Analytical network process, Fuzzy

Posted Date: March 18th, 2021

DOl: https://doi.org/10.21203/rs.3.rs-276992/v1

License: (c) (1) This work is licensed under a Creative Commons Attribution 4.0 International License.

Read Full License

Version of Record: A version of this preprint was published at Environmental Science and Pollution Research on July 1 st, 2021. See the published version at https://doi.org/10.1007/s11356-021-14534-w. 
1 Towards a flood vulnerability assessment of watershed using integration of decision making

2 trial and evaluation laboratory, analytical network process, and fuzzy theories

3 Farzaneh Sajedi Hosseini ${ }^{1}$, Shahram Khalighi Sigaroodi 1*, Ali Salajegheh ${ }^{1}$, Alireza

4 Moghaddamnia ${ }^{1}$, Bahram Choubin ${ }^{2}$

$5{ }^{1}$ Reclamation of Arid and Mountainous Regions Department, Faculty of Natural Resources,

6 University of Tehran, Karaj, Iran.

$7{ }^{2}$ Soil Conservation and Watershed Management Research Department, West Azarbaijan

8 Agricultural and Natural Resources Research and Education Center, AREEO, Urmia, Iran.

$9 \quad{ }^{3}$ Environmental Quality, Atmospheric Science and Climate Change Research Group, Ton Duc

10 Thang University, Ho Chi Minh City, Vietnam.

$11{ }^{4}$ Faculty of Environment and Labour Safety, Ton Duc Thang University, Ho Chi Minh City,

12 Vietnam.

13 Corresponding author: khalighi@ut.ac.ir 


\section{Abstract}

Among natural disasters, flood is increasingly recognized as a serious worldwide concern that causes the most damages in parts of agriculture, fishery, housing, and infrastructure, and strongly affects economic and social activities. Universally, there is a requirement to increase our conception of flood vulnerability and to outstretch methods and tools to assess it. Spatial analysis of flood vulnerability is part of non-structural measures to prevent and reduce flood destructive effects. Hence, the current study proposes a methodology for assessing the flood vulnerability in the area of watershed in a severely flooded area of Iran (i.e., Kashkan Watershed). First interdependency analysis among criteria (including population density, PD; livestock density, LD; percentage of farmers and ranchers, PFR; distance to industrial and mining areas, DTIM; distance to tourist and cultural heritage areas, DTTCH; land use; distance to residential areas, DTRe; distance to road, DTR; and distance to stream, DTS) was conducted using the decision-making trial and evaluation laboratory (DEMATEL) method. Hence, the cause and effect factors and their interaction levels in the whole network were investigated. Then, using the interdependency relationships among criteria, a network structure from flood vulnerability factors to determine their importance of factors was constructed and the analytical network process (ANP) was applied. Finally, with aim of overcome ambiguity, reduce uncertainty, and keep the data availability, an appropriate Fuzzy membership function was applied to each layer by analyzing the relationship of each layer with flood vulnerability. Importance analysis indicated that the variables of land use (0.197), DTS (0.181), PD (0.180), DTRe (0.140), and DTR (0.138) were the most important variables. The flood vulnerability map produced by the integrated method of DEMATEL-ANPFUZZY showed that about $19.2 \%$ of the region has a high to very high flood vulnerability. 
37 Keywords: Flood vulnerability; DEMATEL; Interdependency; Analytical network process;

38 Fuzzy

\section{Introduction}

41 Flood is abundant water that flows rapidly and covers a large area of land, which has not been

42 naturally submerged, and it is known as one of the most destructive disasters (Getahun and Gebre

43 2015). Among natural disasters, flood is increasingly recognized as a serious worldwide concern

44 that causes the most damages in parts of agriculture, fishery, housing, and infrastructure, and

45 strongly affects economic and social activities (Demir and Kisi 2016). During the past several

46 decades, flood has led to high economic damages and human casualties in different regions of the

47 world (Guo et al. 2014). Surveys showed that just in 2010, more than 178 million people

48 worldwide have been affected by floods, and from 1960 to 2017 about $34 \%$ of natural disasters

49 have been caused by floods, resulting yearly about 1254 deaths and $\$ 2.5$ billion in socio-economic

50 damage (Petit-Boix et al., 2017). In Iran, due to the arid and semi-arid climate, the rainfall is mostly

51 short-term and intense which this condition will be exacerbated by climate change. After 1985 the

52 frequency of more extreme floods because of rangeland degradation and intense deforestation has

53 been increased in this country (Modarres et al. 2016). For instance, one of the most devastating

54 events in the contemporary history of Iran was occurred in March 2019, that it involved 28

55 provinces and about $70 \%$ of the country's area with an economic cost of about \$ 3.5 billion U.S.D.

56 (Aminyavari et al. 2019; Hosseini et al. 2020). Thus, one of the basic steps to reduce the harmful

57 effects of floods is to identify flood-prone areas and grade these areas in terms of flood 58 vulnerability (Patial et al. 2008). 
59 Sustainable management of natural resources requires the identification of vulnerable regions that 60 is one of the main steps in the protection framework (Sahoo et al., 2016). According to the

61 Intergovernmental Panel on Climate Change (IPCC) (2014), vulnerability is a degree of sensitivity 62 in a system to the lateral effects of a particular hazard or strain (Field et al., 2014). Understanding 63 effective factors is essential for assessing environmental vulnerability (Burger, 1997). In general, 64 vulnerability refers to the economic, social, physical, and environmental conditions that show the 65 sensitivity of the elements to hazard effects (UNISDR, 2009). Spatial analysis of flood 66 vulnerability is part of non-structural measures to prevent and reduce flood destructive effects 67 (Demir and Kisi 2016).

68 A major area of interest within the field of flood studies is paid attention to flood 69 susceptibility/hazard assessment (e.g., Islam et al. 2020; Nachappa et al. 2020; El-Haddad et al. 70 2020; Costache et al. 2020; Costache and Bui 2020; Tang et al. 2020), but far too little attention 71 has been paid to flood vulnerability assessment and there is not entirely a guideline for its 72 analyzing. However, flood vulnerability analysis is usually conducted using decision-making 73 approaches (Lee et al. 2013). Although, in a study, Connor and Hiroki (2005) analyzed the flood 74 vulnerability using the multiple linear regression through considering the vulnerability as a 75 function of the number of casualties, number of populations, and amount of costs; due to lack of 76 any observed data that can assign as a dependent variable, application of other methods such as 77 machine learning is not feasible. Among the decision-making approaches, analytical hierarchy 78 process (e.g., Ouma and Tateishi 2014; de Brito et al. 2018), Delphi (e.g., de Brito et al. 2017; 79 Boulomytis et al. 2019), TOPSIS (e.g., Lee et al. 2013; Yang et al. 2018) have been applied to 80 flood vulnerability analysis. But the main limitation of these methods is that they have not 81 considered interdependency among criteria (Khadivi and FatemGhomi, 2012). Some studies such 
82 as de Brito et al. (2018) have addressed this issue by using the analytical network process (ANP)

83 method which considers the interdependency among factors through network analysis. However,

84 how to determine the interdependency among factors is another major issue that is not well

85 documented in the flood vulnerability analysis. In this study, we tried to fill this gap by applying

86 the decision-making trial and evaluation laboratory (DEMATEL) method, which can extract

87 interdependencies among variables (Sajedi-Hosseini et al. 2018).

This study, therefore, set out to assess the flood vulnerability at the watershed level. We integrated the DEMATEL, ANP, and Fuzzy theories to develop a methodology for flood vulnerability assessment. It should be noted that one of the main aspects and effective ways in modern flood management and flood damage mitigation is increasing the awareness and perception of people to floods (Kellens et al. 2011). To achieve this purpose, having flood vulnerability maps may help managers to gain a deeper understanding of vulnerable areas.

\section{Materials and methods}

\subsection{Study area}

Kashkan Watershed located in the Lorestan Province, west of Iran, has an area of about $9510 \mathrm{~km}^{2}$ which extends from longitudes $47^{\circ} 12^{\prime} 03^{\prime \prime}$ to $48^{\circ} 59^{\prime} 42^{\prime \prime}$ east and latitudes $33^{\circ} 04^{\prime} 24^{\prime \prime}$ to $34^{\circ} 03^{\prime}$ 36" north (Figure 1). The basin is an important tributary of the Karkheh River Basin (the main River Basin in the west of Iran). Variation of the elevation in the watershed is high and vary between $527 \mathrm{~m}$ to $3630 \mathrm{~m}$. Cites of Khorramabad, Kuhdasht, Aleshtar, Firozabad, and Pol-e Dokhtar with a sum of about 800,000 people are in this watershed (National Statistics Center of Iran, 2016) (Figure 1). The long-term mean precipitation of the Kashkan Watershed is about 620 mm (JAMAB, 1999). According to available statistics during the last fifty years, this watershed is 
105 the most flooded area in the Lorestan Province and Iran. For example, one of the biggest and most 106 destructive floods in this watershed was occurred in March 2019, with a peak of $3000 \mathrm{~m}^{3} / \mathrm{s}(\sim 300-$ $107 y r$ return period) (Geravand et al. 2020). Figure 2 indicates a small part of the damage of this flood 108 in the region. The main land uses of the watershed are rangeland $(34.87 \%)$, forest $(34.44 \%)$, 109 agriculture $(27.57 \%)$, residential $(2.0 \%)$, orchard $(0.92 \%)$, and others $(0.2 \%)$. 

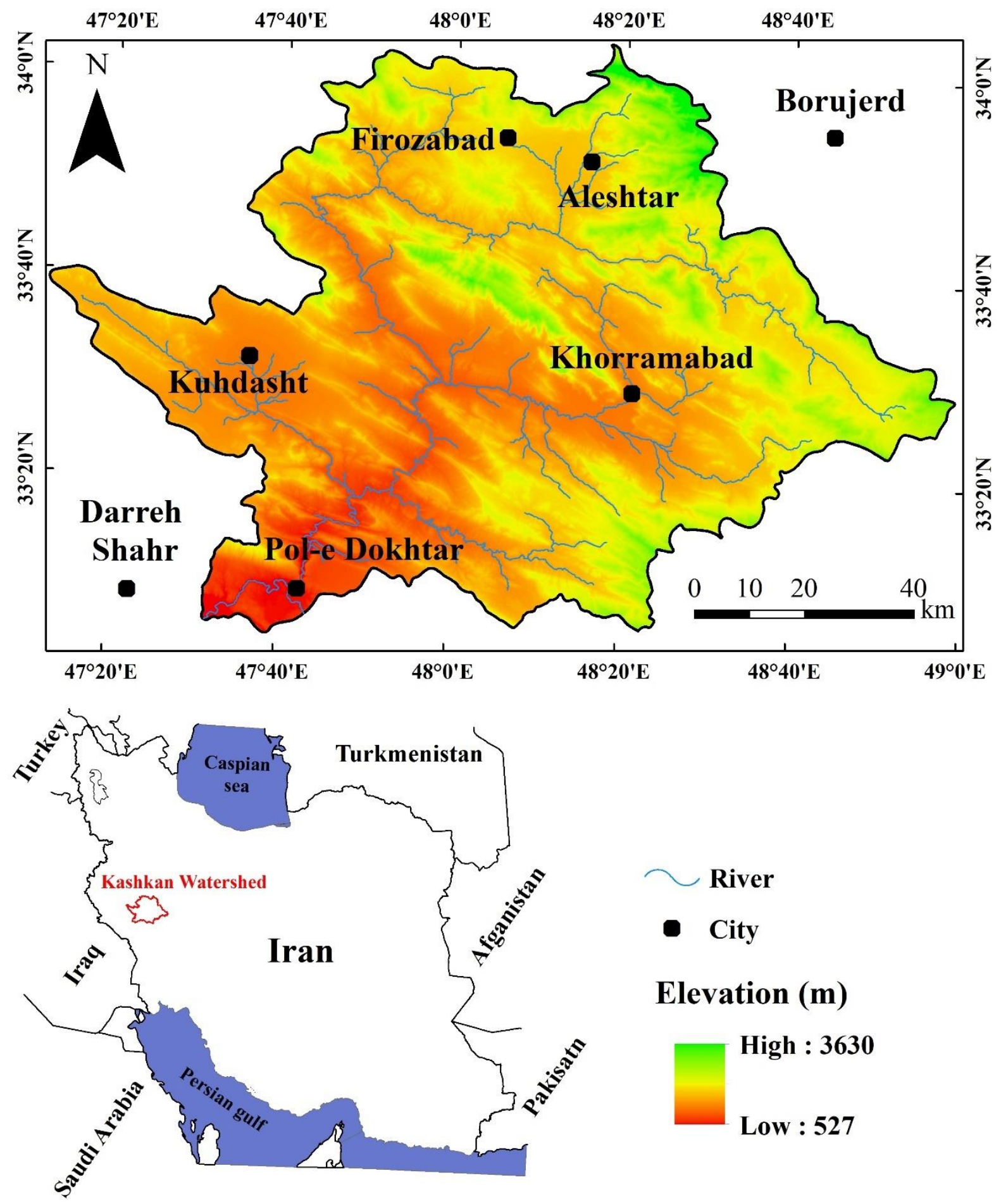

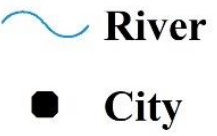

Elevation (m)

Figure 1. Location of the study area. 

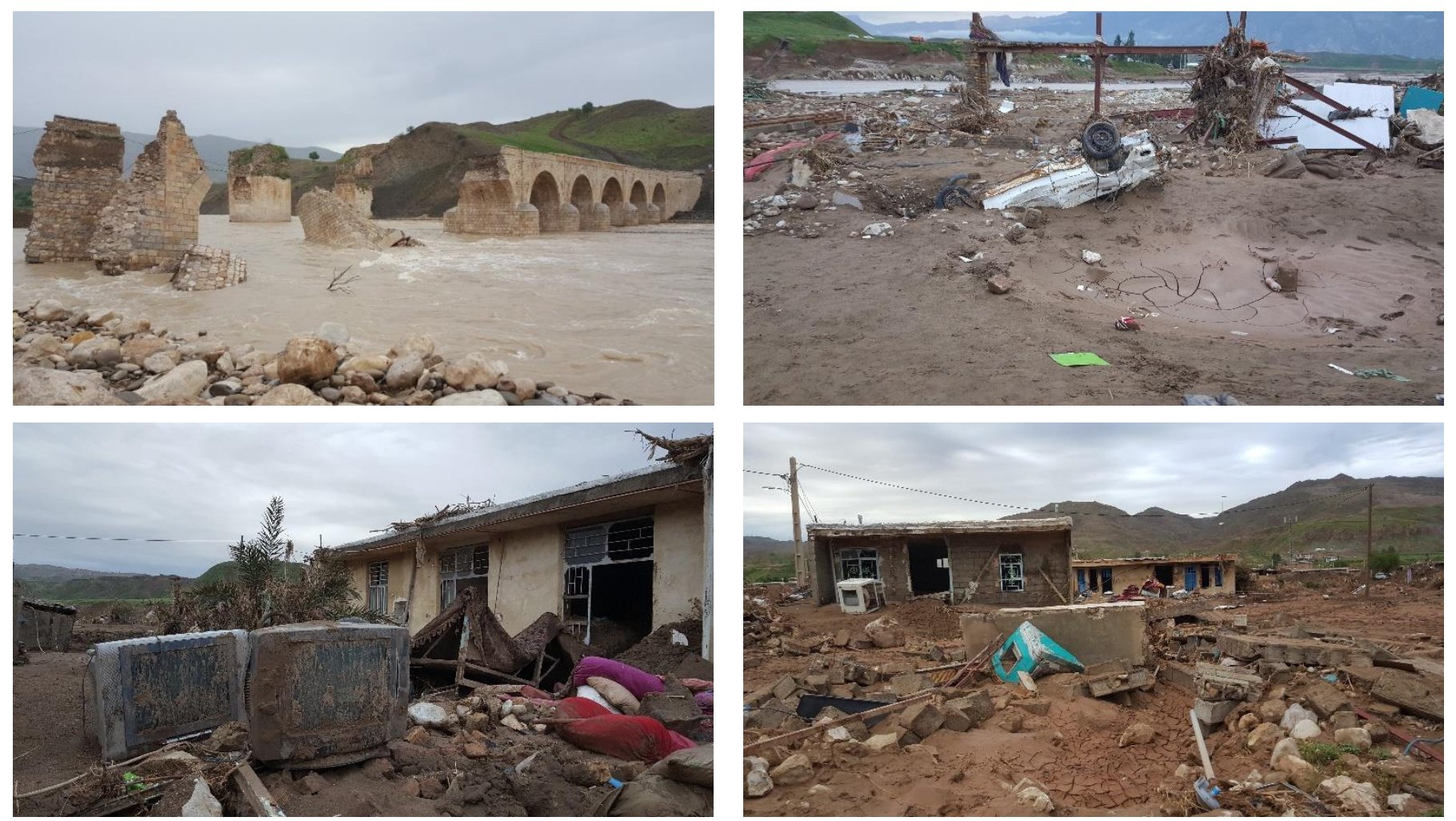

Figure 2. Some photos of the flood damage in March 2019. Photos were taken by Shahram

\subsection{Flood vulnerability factors}

120 According to the surveys in literature, applied factors for vulnerability assessment are consist of

121 physical, economic, and social conditions (e.g., Karmaoui et al. 2016; Sadeghi-Pouya et al. 2017;

122 Kumar and Bhattacharjya 2020). Thus, in this study, we considered important physical and socio-

123 economic factors based on the available data in the area of the watershed; that are described as

124 follows:

\subsubsection{Socio-economic factors}

126 Socio-economic factors are including the population density (PD), livestock density (LD),

127 percentage of farmers and ranchers (PFR), distance to industrial and mining areas (DTIM), 
128 distance to tourist and cultural heritage areas (DTTCH), and land use (Figure 3a to 3f). For 129 preparing the above-mentioned factors, data including the number of population, number of 130 livestock, PFR, location of industrial and mining areas, and location of tourist and cultural heritage 131 areas were obtained from the National Statistics Center of Iran according to the general population 132 and housing census and agricultural census during 2016 (National Statistics Center of Iran, 2016).

133 PD and LD indicate respectively the number of people and livestock in a given area (usually at $134 \mathrm{~km}^{2}$ ). Everywhere the PD and LD are more, the flood vulnerability is greater. PFR shows the 135 percentage of people engage in agriculture and rancher, which vulnerability can increase as the 136 PFR increases. To prepare the maps of DTIM and DTTCH, the Euclidean distance tools in ArcGIS 13710.3 was used. By increasing the DTIM and DTTCH, the flood vulnerability is decreased. Land 138 use was another effective factor that was used for flood vulnerability assessment. Different land 139 uses have different values and different reactions to flood; for example, residential areas and 140 infrastructures such as roads are most important, while they reduce soil infiltration capacity and 141 increase runoff (Ouma and Tateishi, 2014). To prepare the land use map, the required frames of 142 the Sentinel 2 in April 2017 were obtained. Then after taking the data samples from Google Earth 143 and field surveys, the area was classified into seven categories (including forest, rangeland, 144 agriculture, barren, orchard, residential, and waterbody) using the Maximum Likelihood 145 Classification (MLC) method in ENVI 5.4 environment.

\subsubsection{Physical factors}

147 Physical factors are including the distance to residential areas (DTRe), distance to road (DTR), 148 and distance to stream (DTS) (Figure 3g to 3i). By decreasing the distance to residential areas, 149 roads, and streams, the vulnerability is increased. The location of residential areas was extracted 150 by the land use map. The road layer was received from the Iranian Water Resources Management 
151 Company (IWRMC). For extracting the stream layer, we used a Digital Elevation Model (DEM) 152 with a pixel size of about $13 \times 13 \mathrm{~m}$ (for the study area in Iran) which was obtained from Sentinel 1531 satellite images. Then, the stream layer was prepared in the ArcGIS 10.3 software by extension 154 of the ArcSWAT 2012.10.3.19. For preparing the all physical factors shown in Figure $3 \mathrm{~g}$ to $3 \mathrm{i}$, the 155 Euclidean distance tools in ArcGIS 10.3 was applied.

156 It should be mentioned that all socio-economic and physical factors were resampled to a pixel size $15713 \times 13 \mathrm{~m}$ to be equal with land use and DTS layers obtained from the Sentinel images. 


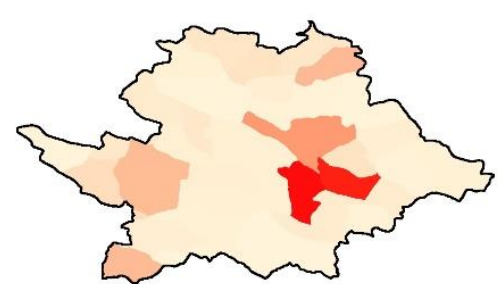

(a) $\operatorname{PD}\left(\mathrm{n} / \mathrm{km}^{2}\right)$

High : 590

Low : 6

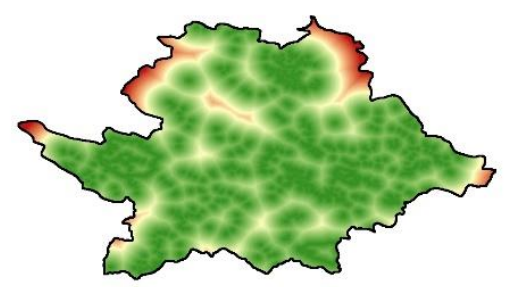

(d) DTIM (m)

High : 18960

Low : 0

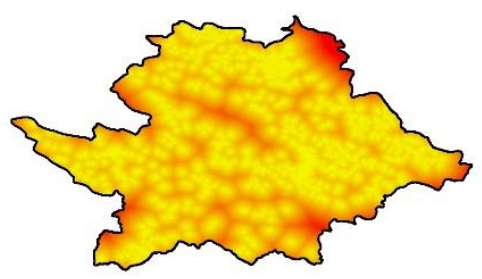

(g) DTRe (m)

High : 18150

Low : 0

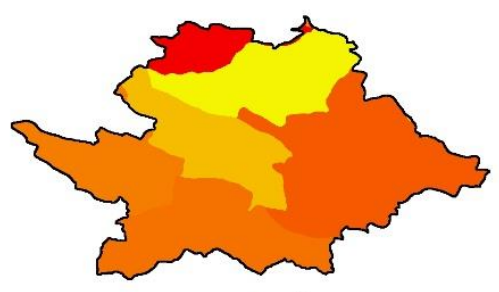

(b) $\mathbf{L D}\left(\mathrm{n} / \mathrm{km}^{2}\right)$

High : 81

Low : 5

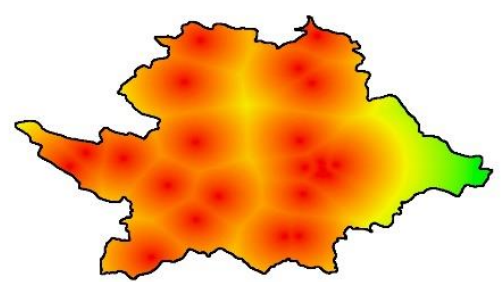

(e) DTTCH (m)
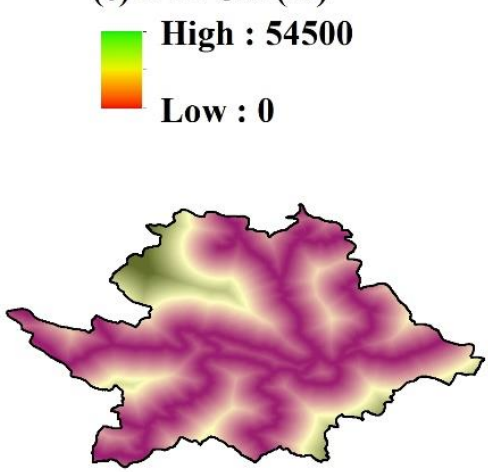

(h) DTR (m)

High : 29780

Low : 0

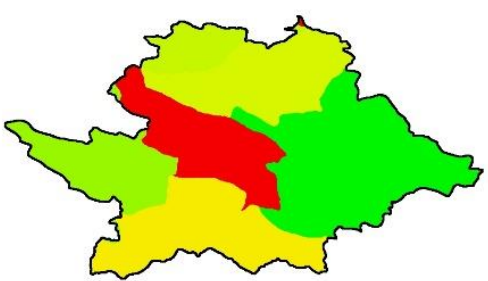

(c) PFR (\%)

High : 46

Low : 8

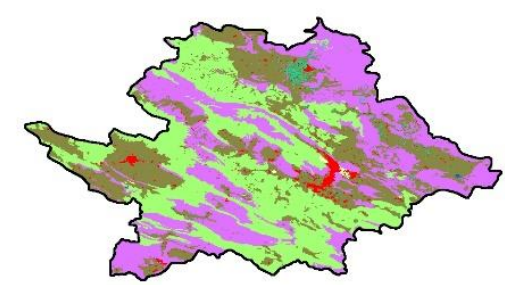

(f) Landuse Agriculture $\checkmark$ Residential Forest Orchard Waterbody Rangeland

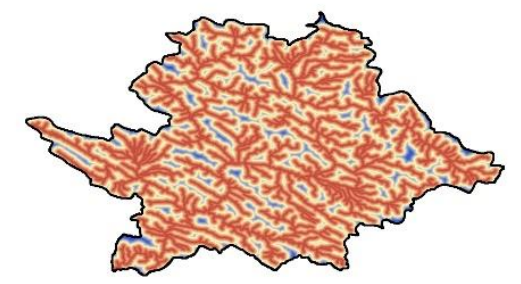

(i) DTS (m)

High : 6815

Low : 0

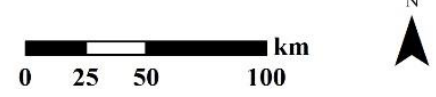

$\hat{A}$

Figure 3. Flood vulnerability variables: (a) population density (PD), (b) livestock density (LD), (c) percentage of farmers and ranchers (PFR), (d) distance to industrial and mining areas (DTIM), (e) distance to tourist and cultural heritage areas (DTTCH), (f) land use, (g) distance to residential areas (DTRe), (h) distance to road (DTR), and (i) distance to stream (DTS). 
168 The procedure of flood vulnerability assessment in this study is divided into four steps: (i) 169 investigation of the relationships among factors using the Decision Making Trial and Evaluation 170 Laboratory (DEMATEL), (ii) calculation of the weight of factors using the Analytical Network

171 Process (ANP) and identified relationships from step (i), (iii) standardizing pixels based on the 172 relevance fuzzy membership functions, and (iv) flood vulnerability mapping; which, they are 173 described as follows:

\subsubsection{Investigation of the relationships among factors using the DEMATEL}

176 The DEMATEL method in this study was used to identify the causal relationships among the 177 variables, that it is important in the designing network in the ANP method. According to this 178 method, number of 30 questionnaires was distributed and completed by the related specialists, and 179 the influence of the factors on each other was investigated via values of $0,1,2,3$, and 4 respectively 180 for 'No', 'Very low', 'Low', 'High', and 'Very high' effects (Gabus and Fontela 1972; Azareh et 181 al. 2019). The steps of the DEMATEL method can be summarized as follows (Gabus and Fontela 182 1972; Sajedi-Hosseini et al. 2018):

183 (i) A matrix $M_{n \times n}$ is prepared based on the experts' knowledge that indicates the influence of the factors on each other (base on the above-mentioned values).

185 (ii) The matrix $M_{n \times n}$ is normalized $(N)$ using the Eq.s 1 and 2: $N=K \cdot M_{n \times n} \quad$ Eq. 1 $K=\frac{1}{\max \sum_{j=1}^{n} a_{i j}}$ and $1 \leq i \leq n \quad$ Eq. 2 in the matrix $M_{n \times n}$, and $a_{i j}$ denotes the influence of factor $i$ on factor $j$. 
(iii) Total relation matrix $(T)$ is calculated by using the identity matrix $(I)$ through the Eq.

In the current research, the DEMATEL method was run in the MATLAB R2016b.

\subsubsection{Weight calculation of the factors using the ANP}

204 In this study, the ANP method was used to determine the weight of factors. The method is one of 205 between two nodes is called the external dependence that represented by the two-way arrow, and

211 the internal interdependence between the elements in a node is represented by a loop arrow (Saaty 212 2005). According to Saaty (2001), the ANP method can be summarized in five steps as follows: 
(i) Design and conversion of the problem to a network structure. In this study, the cause and effect factors and their dependencies were determined by the DEMATEL method.

(ii) Pairwise comparison. In this step, the comparison of factors was done using the linguistic terms and scale 1 to 9 Saaty (2001).

(iii) Creation of the primary supermatrix according to the weights obtained from step (ii).

(iv) Creation of the weighted supermatrix by multiplying the primary supermatrix by weight of clusters.

(v) Eventually, calculation of the limited supermatrix was done by multiplying the weighted supermatrix $n$ times by itself.

More information about the ANP method has been described by Saaty (2001). In this study, the ANP method was implemented within the environment of SuperDecision 2.8 software.

\subsubsection{Standardizing pixels based on the fuzzy membership functions}

After calculating the layers' weight using the DEMATEL-ANP method, the pixels of each layer were standardized based on the relative fuzzy membership functions. According to the scholars (e.g., Sajedi-Hosseini et al. 2018; Azareh et al. 2019), providing the continuous values based on the Fuzzy keep the data variability of variables that is more realistic than other ways such as categorizing inputs. Also, the Fuzzy can overcome ambiguity and reduce uncertainty (Samanlioglu and Aya 2016; Sajedi-Hosseini et al. 2018). Thus, by analyzing the relationship of each layer with flood vulnerability, an appropriate fuzzy membership function was applied for standardizing each layer between 0 and 1 . In this study, we used the Fuzzy membership tools in the ArcGIS 10.3 for this objective. 
237 Following the above steps, the flood vulnerability map was calculated using the Raster Calculator

238 Tools in the ArcGIS 10.3 by the Eq. 7:

$239 \quad F V=\frac{\sum_{i=1}^{i=n} W_{i} \times N_{i}}{\sum_{i=1}^{i=n} W_{i}} \quad$ Eq. 7

240 where $F V$ indicates the flood vulnerability, $W_{i}$ is the weight of variable $i$ calculated by the

241 DEMATEL-ANP method, $N_{i}$ is a normalized layer of variable $i$ by the related fuzzy membership

242 function, and $n$ is the number of variables. A higher value of the $F V$ shows a higher flood

243 vulnerability.

244 After calculating the $F V$ layer, it is reclassed into five classes of very low, low, moderate, high, 245 and very high flood vulnerability using the Equal interval method (via an interval 0.2 from 0 to 1 ) 246 in the ArcGIS 10.3.

247

248 3. Results and Discussion

\subsection{Causal relations between factors based on the DEMATEL method}

250 Finding the causal relationships between factors is important for designing an appropriate network

251 from the problem across the ANP method. Results of causality analysis by the DEMATEL are 252 presented in Table 1 and Figure $4 . R_{i}$ and $C_{i}$ are respectively sum of rows and columns within the 253 total relation matrix (Eq. 3), which indicates the magnitude of the cause and effect of each variable. 254 Accordingly, $R_{i}-C_{i}$ is named as 'relation' that is used to determine whether a variable is a cause $255\left(R_{i}-C_{i}>0\right)$ or effect $\left(R_{i}-C_{i}<0\right)$ factor in the whole network (Sajedi-Hosseini et al. 2018; Azareh 256 et al. 2019). According to the results (Table 1 and Figure 4), variables of distance to stream (DTS),

257 distance to industrial and mining areas (DTIM), distance to residential areas (DTRe), and distance 
258 to road (DTR) are causal factors in the whole network, while variables of land use, distance to

259 tourist and cultural heritage areas (DTTCH), percentage of farmers and ranchers (PFR), population

260 density (PD), and livestock density (LD) are effect factors in the whole network. $R_{i}+C_{i}$ is named

261 as 'prominence' that is used to indicate which variables have the highest total interaction in the

262 whole network. The results indicated that the variable of distance to road (DTR), land use,

263 population density (PD), and distance to stream (DTS) have the highest interaction with other

264 variables (Table 1 and Figure 4).

265 Finally, according to the DEMATEL results by defining a threshold on values of the total relation

266 matrix, the structure of the network among the flood vulnerability factors are designed (Figure 5).

267 The direction of the arrows shows the effect of a factor on another. The interdependency effect

268 between two variables represented by a two-way arrow (Figure 5).

Table 1. Results of causality analysis by the DEMATEL method

\begin{tabular}{lcccc}
\hline Factor & $\begin{array}{c}\mathrm{Ri} \\
\text { (Cause) }\end{array}$ & $\begin{array}{c}\mathrm{Ci} \\
\text { (Effect) }\end{array}$ & $\begin{array}{c}\mathrm{Ri}-\mathrm{Ci} \\
\text { Relation)(Prominence) }\end{array}$ \\
\hline Distance to stream (DTS) & 3.34 & 2.14 & 1.2 & 5.48 \\
Distance to industrial and mining areas (DTIM) & 2.39 & 1.69 & 0.7 & 4.08 \\
Distance to residential areas (DTRe) & 2.7 & 2.27 & 0.43 & 4.97 \\
Distance to road (DTR) & 3.27 & 2.9 & 0.37 & 6.17 \\
Land use & 2.94 & 3.07 & -0.14 & 6.01 \\
Distance to tourist and cultural heritage areas & 1.12 & 1.55 & -0.42 & 2.67 \\
(DTTCH) & 2.24 & 2.72 & -0.49 & 4.96 \\
Percentage of farmers and ranchers (PFR) & 2.64 & 3.27 & -0.63 & 5.91 \\
Population density (PD) & 1.07 & 2.1 & -1.03 & 3.17 \\
Livestock density (LD) & & &
\end{tabular}




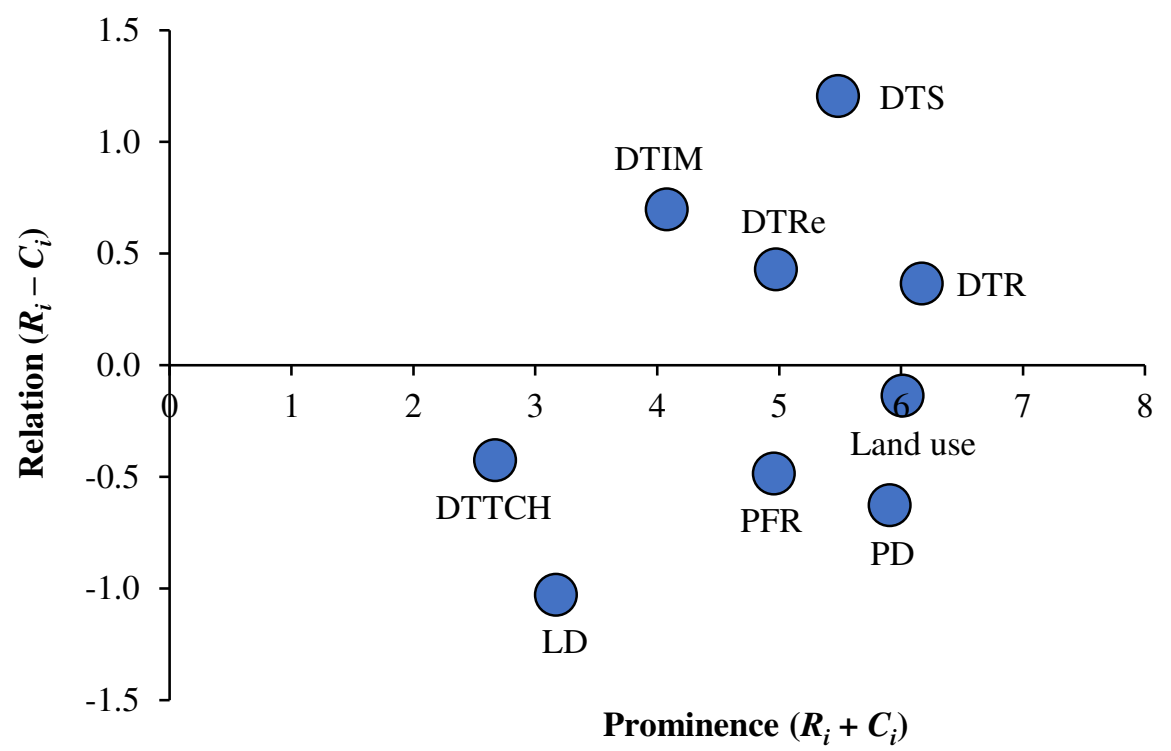

272

273 Figure 4. Causal diagram representing the relation (cause/effect) and prominence (interaction) of the variables in the whole network.

275

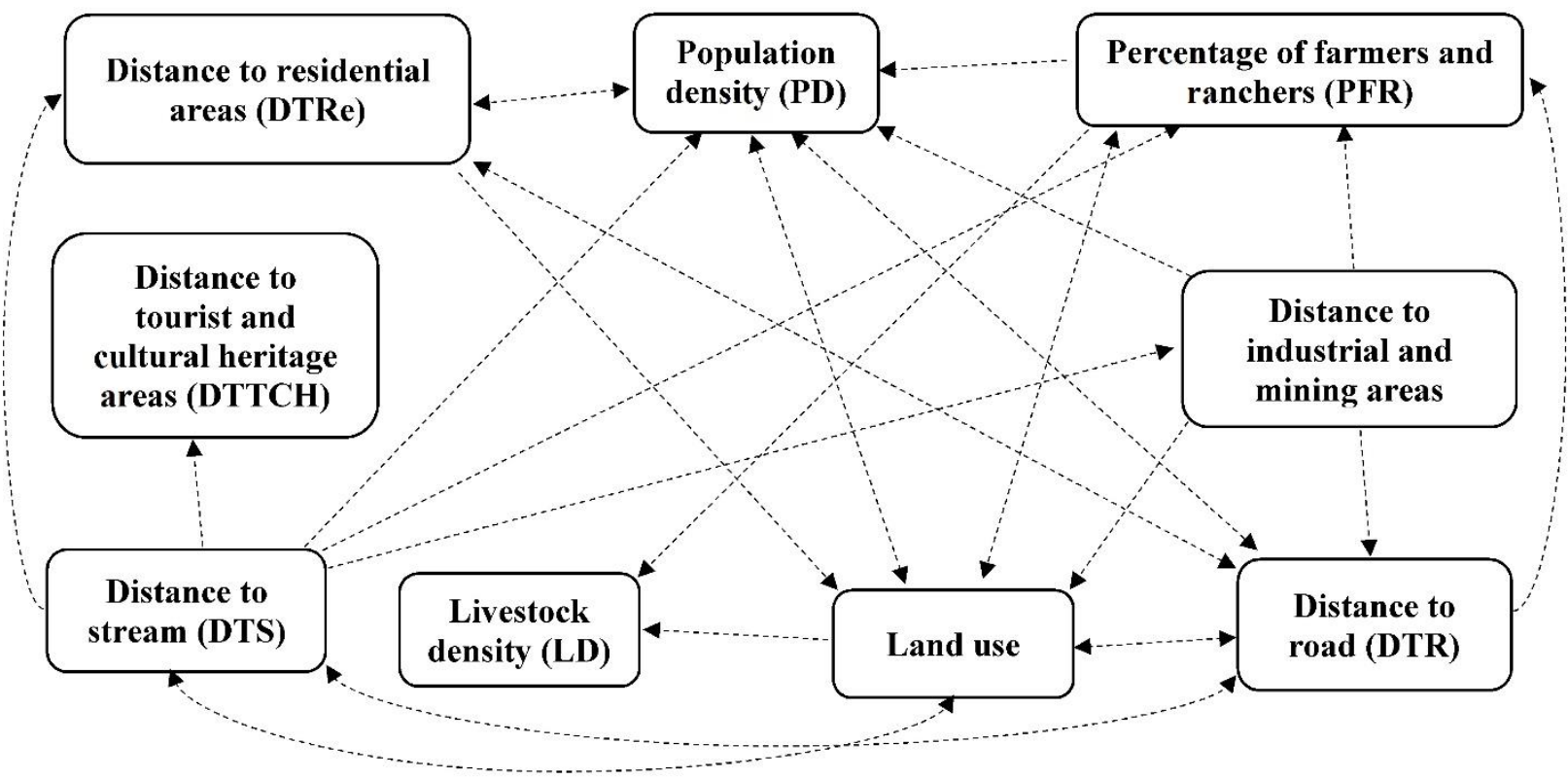

Figure 5. Designed network structure among the flood vulnerability variables by the DEMATEL 
280 After determining the relationships between variables and designing the network structure, the 281 ANP method was used for extracting the importance and weight variables. According to the ANP282 DEMATEL results, variables of land use (0197), distance to stream (DTS) (0.181), population 283 density (PD) (0.180), distance to residential areas (DTRe) (0.140), and distance to road (DTR) 284 (0.138) were the most important variables, respectively (Table 2). While, variables of distance to 285 tourist and cultural heritage areas (DTTCH) (0.010), livestock density (LD) (0.019), distance to 286 industrial and mining areas (DTIM) (0.065), and percentage of farmers and ranchers (PFR) (0.070) 287 were the less important factors, respectively, that calculated by the ANP- DEMATEL method 288 (Table 2).

289 No reference has used the DEMATEL-ANP method for flood vulnerability assessment in the area 290 of the watershed. So, it is not possible to compare the results with previous studies. Although in 291 other fields such as flood susceptibility mapping this method has been used (e.g., Azareh et al. 292 2019), the comparison of the results is not the right way because the concepts and effective factors 293 of the flood susceptibility are different from the flood vulnerability. Indeed, the flood vulnerability 294 detects the potential weaknesses and strengths in the region, not the actual flood hazard (Fekete, 295 A., 2009.).

Table 2. Importance of the factors based on the ANP method

\begin{tabular}{lc}
\hline Factors & Weight \\
\hline Land use & 0.197 \\
Distance to stream (DTS) & 0.181 \\
Population density (PD) & 0.180
\end{tabular}




\begin{tabular}{ll}
\hline Distance to residential areas (DTRe) & 0.140 \\
Distance to road (DTR) & 0.138 \\
Percentage of farmers and ranchers (PFR) & 0.070 \\
Distance to industrial and mining areas (DTIM) & 0.065 \\
Livestock density (LD) & 0.019 \\
Distance to tourist and cultural heritage areas (DTTCH) & 0.010 \\
\hline
\end{tabular}

300 One of the most important steps in network analysis is to assess the validity and consistency of 301 pairwise comparisons. It derives us to decompose complexity into a network structure for a better 302 understanding of the relationship between its components and to create priorities for them within 303 that structure (Ozdemir 2005). The issue of consistency is important in complex and multi-criteria 304 issues, hence, the existence of a technique that can comment on the consistency of any decision is 305 of great importance. Inconsistency causes errors and a lack of certainty to get logical and true 306 results (Davvodi 2009). Inconsistency rate (IR) is an indicator that reflects the possible 307 contradictions and inconsistencies in the pairwise comparison matrix. A valid result is obtained 308 when the inconsistency rate is less than 0.1 (Tummala and Wan 1994). Accordingly, the 309 inconsistency values of the pairwise comparisons for each node across the ANP method are 310 presented in Table 4. The pairwise comparisons in all the nodes indicate the validity of the results $311 \quad(\mathrm{IR}<0.1)$.

313 Table 3. Inconsistency value of pairwise comparisons for each node across the ANP method

\begin{tabular}{ll}
\hline Node & Inconsistency rate \\
\hline
\end{tabular}




\begin{tabular}{lc}
\hline Land use & 0.097 \\
Distance to stream (DTS) & 0.00 \\
Population density (PD) & 0.091 \\
Distance to residential areas (DTRe) & 0.028 \\
Distance to road (DTR) & 0.061 \\
Percentage of farmers and ranchers (PFR) & 0.015 \\
Distance to industrial and mining areas (DTIM) & 0.00 \\
Livestock density (LD) & 0.00 \\
Distance to tourist and cultural heritage areas (DTTCH) & 0.00 \\
Flood vulnerability & 0.079 \\
\hline
\end{tabular}

\subsection{Flood vulnerability mapping}

316 After validation of the ANP-DEMATEL model and ensuring the results, an appropriate

317 membership function (MF) was applied for standardizing each layer between 0 and 1 . The applied 318 fuzzy MF for each variable is presented in Table 4. Linear-increasing MF was used for 319 standardizing the layers of LD, PD, and PFR. It means that by increasing the pixels' value of these 320 layers, the flood vulnerability is increased. Linear-decreasing MF was applied for standardizing

321 the layers of DTS, DTR, DTRe, DTIM, and DTTCH. It means that by increasing the pixels' value 322 of these layers, the flood vulnerability is decreased (Table 4). So, in linear-increasing (linear323 decreasing) MF, the higher (lower) value of a layer converts to 1 and the lower (higher) value 324 converts to 0 , and other values change between them. For land use layer, fuzzy values of $0.2,0.4$, $3250.4,0.4,0.7,0.8$, and 1 respectively for barren land, rangeland, forest, waterbody, orchard, 326 agriculture, and residential area were considered (according to the expert knowledge). By defining 327 an appropriate membership function to each layer, each pixel gets a value that indicates 328 vulnerability of that pixel to flooding. Accordingly, values of pixels in each layer convert into a 
329 continuous scale from 0 to 1 based on the target (i.e., flood vulnerability) that keeps the data 330 availability in the overlaying process (Sajedi-Hosseini et al. 2018; Azareh et al. 2019). Figure 6

331 shows the normalized factors after applying the fuzzy MF to each layer.

Table 4. Applied fuzzy membership function for each layer

\begin{tabular}{lc}
\hline Factor & Membership function \\
\hline Livestock density (LD) & Linear-increasing \\
Population density (PD) & Linear-increasing \\
Distance to stream (DTS) & Linear-decreasing \\
Listance to road (DTR) & Linear-decreasing \\
Distance to residential areas (DTRe) & Linear-decreasing \\
Distance to industrial and mining areas (DTIM) & Linear-decreasing \\
Distance to tourist and cultural heritage areas (DTTCH) & Linear-decreasing \\
Percentage of farmers and ranchers (PFR) & Linear-increasing \\
& User defined (0.2, 0.4, 0.4, 0.4, 0.7, \\
& 0.8, and 1 for barren land, rangeland, \\
Land use & forest, waterbody, orchard, \\
agriculture, and residential area, & respectively) \\
\hline
\end{tabular}



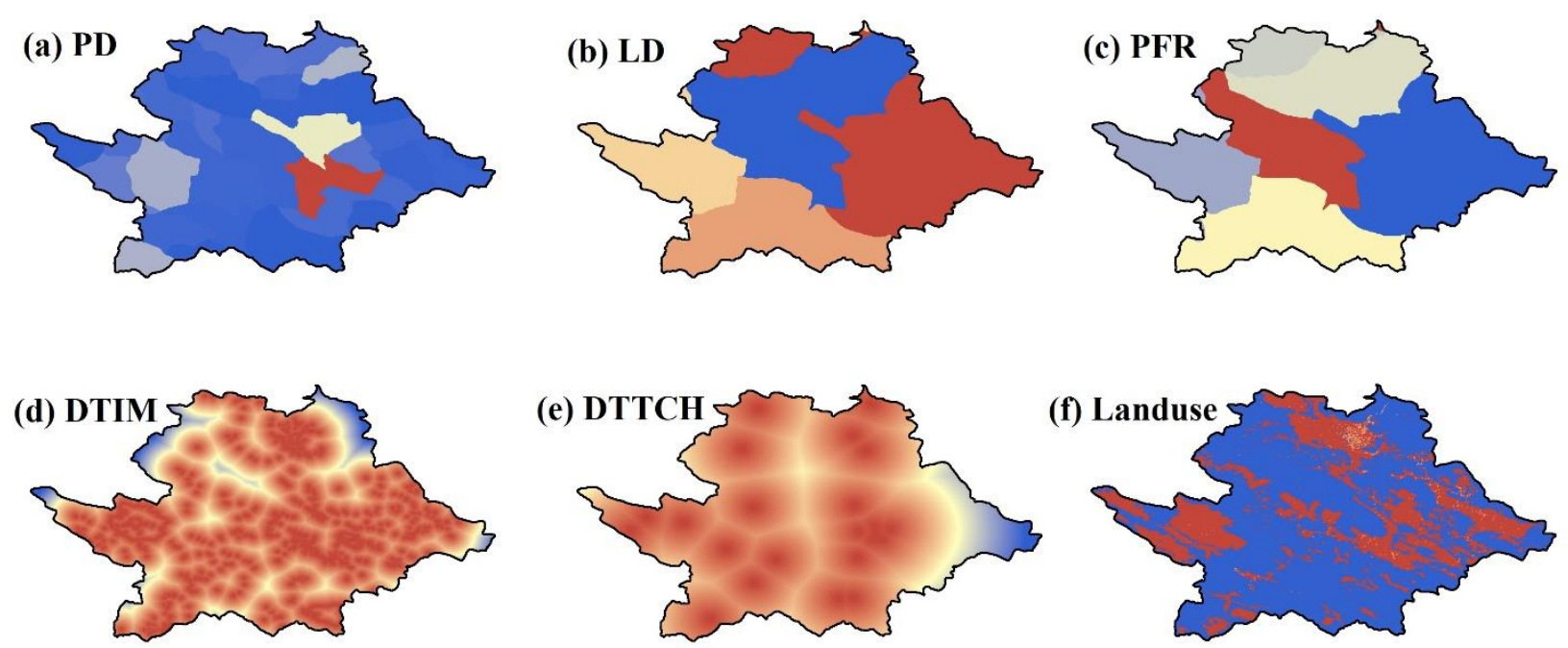

(e)
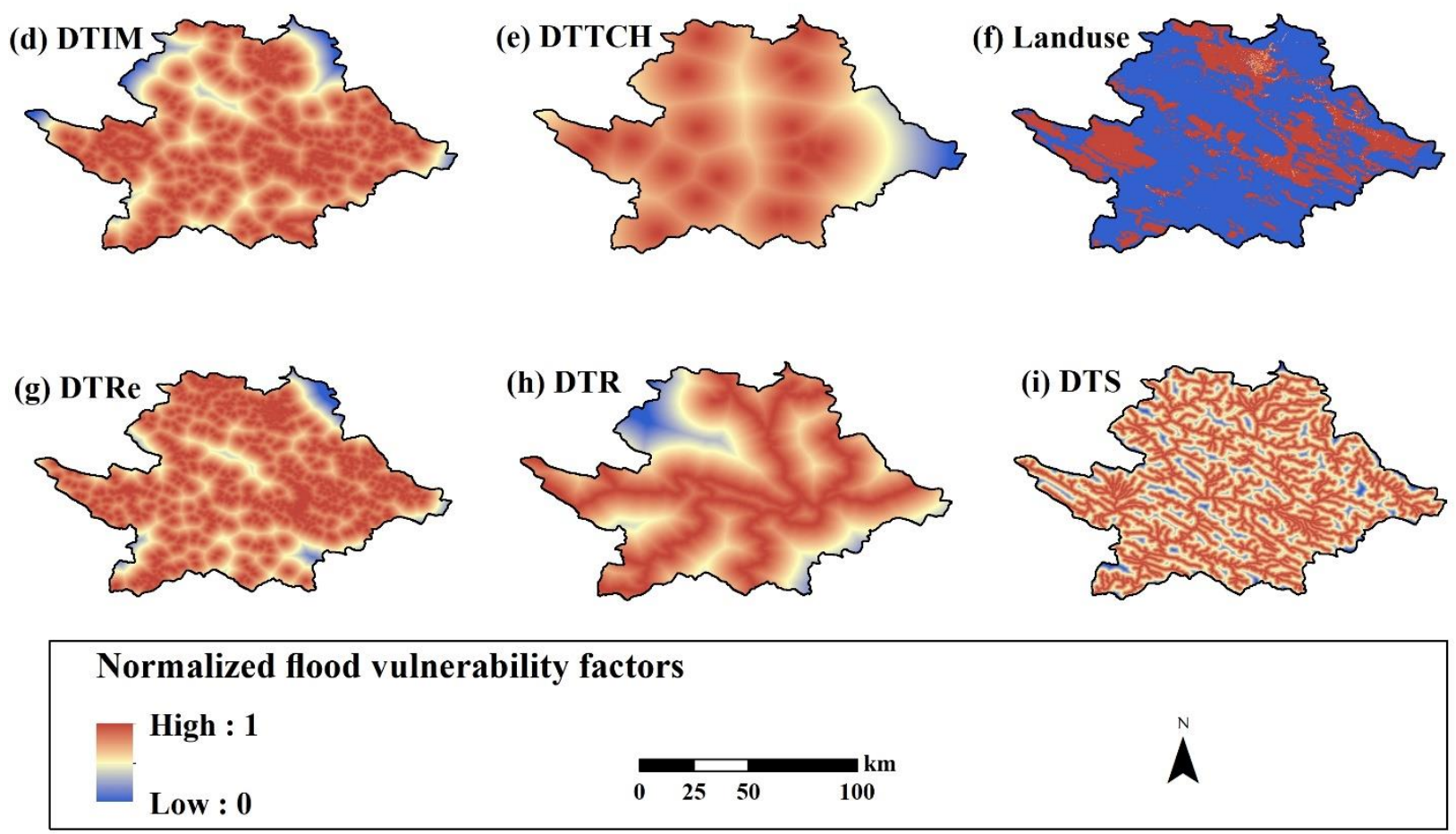

Figure 6. Normalized flood vulnerability factors: (a) population density (PD), (b) livestock density (LD), (c) percentage of farmers and ranchers (PFR), (d) distance to industrial and mining areas (DTIM), (e) distance to tourist and cultural heritage areas (DTTCH), (f) land use, (g) distance to residential areas (DTRe), (h) distance to road (DTR), and (i) distance to stream (DTS).

Finally, by applying the weights achieved from the DEMATEL-ANP method into each Fuzzy layer within ArcGIS 10.3, the overlaying of the layers was conducted using Eq. 7. So, a flood vulnerability map with pixel size $13 \times 13 \mathrm{~m}$ for the area of Kashkan watershed was produced (Figure 7). According to the flood vulnerability map (Figure 7), $47.2 \%$ area of the region (about $4489.5 \mathrm{~km}^{2}$ ) indicates a moderate vulnerability, while other classes of very low, low, high, and 
346 very high contain $1.9 \%\left(182.5 \mathrm{~km}^{2}\right), 31.7 \%\left(3010.5 \mathrm{~km}^{2}\right), 16.9 \%\left(1605.2 \mathrm{~km}^{2}\right)$, and $2.3 \%(222.6$

$347 \mathrm{~km}^{2}$ ) of the region, respectively. Results indicated that the high and very high vulnerability areas

348 correspond to high population density, land use of residential, and low distance to streams. The

349 very high class in Figure 7 is correspond with the location of Khorramabad, Pol-e Dokhtar, and

350 Kuhdasht cities (presented in Figure 1). Some of these very high vulnerable locations (such as

351 vulnerable areas in the Pol-e Dokhtar city) have been previously confirmed by the authors

352 observations from flood damages in March 2019 (Figure 2), after occurring one of the biggest and

353 most destructive floods in this watershed. 


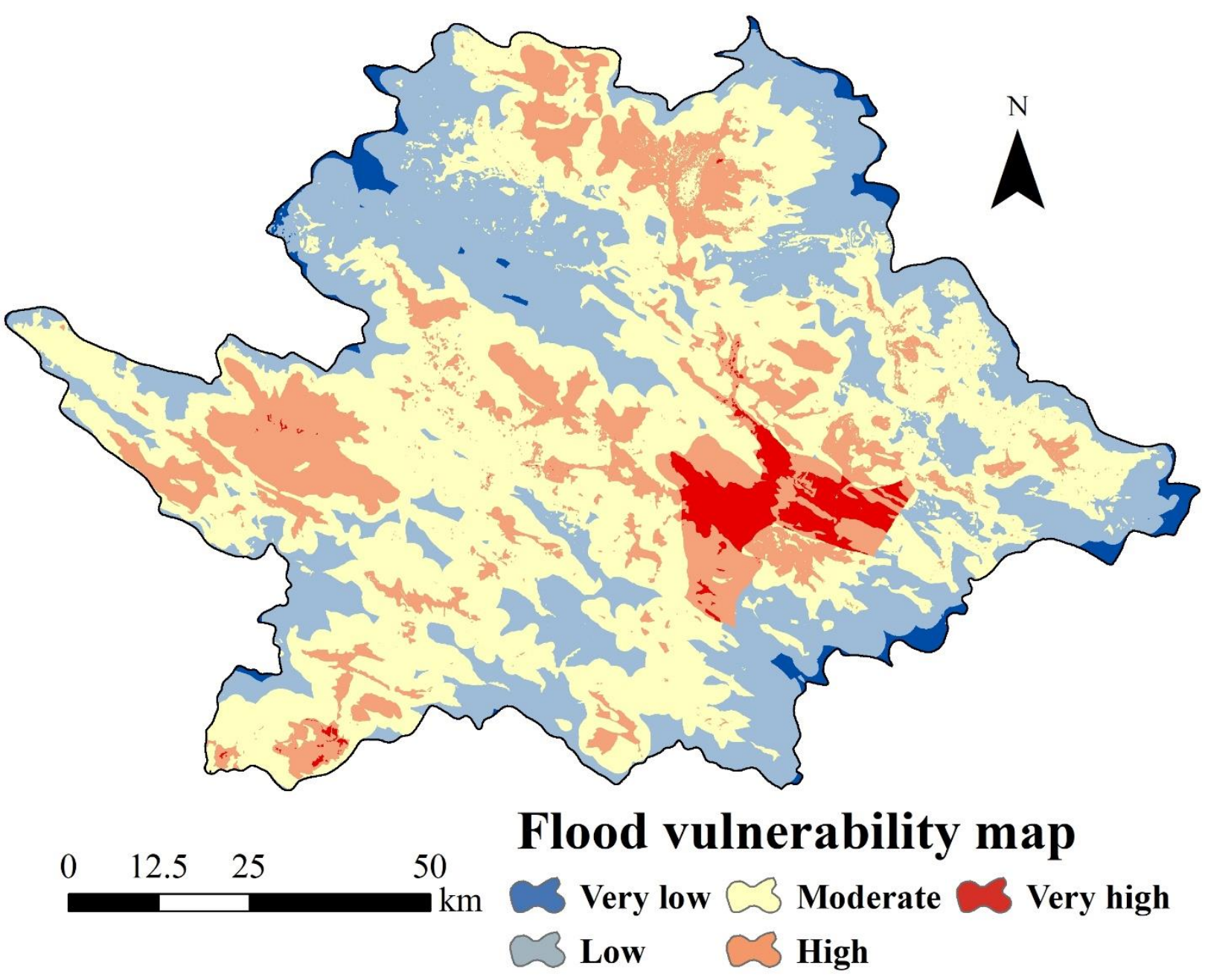

Figure 7. Flood vulnerability map in the Kashkan watershed.

\section{Conclusion}

359 The current study tried to develop a flood vulnerability analysis using an integrated approach by 360 combining the DEMATED, ANP, and Fuzzy methods. The DEMATEL, as a causality analysis 361 method identified the interdependency among factors of flood vulnerability, the ANP determined 362 the importance of factors, and the fuzzy was used to keep the data availability by assigning a 
363 continuous scale to each layer (based on its relationship with flood vulnerability). The ANP-

364 DEMATEL results indicated that the variables of land use (0.197), distance to stream (0.181), 365 population density $(0.180)$, distance to residential areas $(0.140)$, and distance to road $(0.138)$ were 366 the most important variables. According to the flood vulnerability map, $16.9 \%\left(1605.2 \mathrm{~km}^{2}\right)$ and $3672.3 \%\left(222.6 \mathrm{~km}^{2}\right)$ of the region, respectively are located in high and very high flood susceptibility, 368 which are correspond to high population density, land use of residential, and low distance to 369 streams. Validation of the vulnerability areas is an inevitable limitation in the vulnerability studies, 370 even though some of the very high vulnerable locations have been validated by the authors' 371 observations from flood damages after occurred flood in March 2019. Unlike the flood hazard 372 studies, there is not any data for validation of the flood vulnerability map, because the flood 373 vulnerability only detects the potential weaknesses and strengths in the region, not the actual flood 374 hazard. So, the flood vulnerability is regarded as independent of the flood hazard and the location 375 of flooded areas can not be used for flood vulnerability validation. However, in this research, the 376 validity of the DEMATEL-ANP method was confirmed by assessing the inconsistency rate in the 377 network structure. Thus, it is not surprising that there is not any feasible way for additional 378 validation, yet, and it can be an outlook for future researches. 


\section{Declarations}

Ethics approval: Not applicable

387 Consent to participate: Not applicable

Consent to Publish: Not applicable

Authors Contributions: Conceptualization, FSH; Data preparation, FSH; Formal analysis, FSH, $\mathrm{AS}$, and $\mathrm{BC}$; Investigation, FSH, AM, and AS; Methodology, FSH and SKS; Project administration, FSH and SKS; Supervision, SKS; Validation, SKS; Visualization, FSH and BC; Writing - original draft, FSH and BC; Writing - review \& editing, SKS and AM

Funding: The authors received no specific funding for this work.

394 Competing interests: The authors declare that they have no conflict of interests.

Availability of data and materials: The data that support the findings of this study are available 396 from the corresponding author, [S.K.S.], upon reasonable request.

\section{References}

Aminyavari, S., Saghafian, B. and Sharifi, E., 2019. Assessment of Precipitation Estimation from

400 the NWP Models and Satellite Products for the Spring 2019 Severe Floods in Iran. Remote $401 \quad$ Sensing, 11(23), p.2741.

402 Azareh A., Rafiei Sardooi E., Choubin B., Barkhori S., Shahdadi A., Adamowski J., Shamshirband 403 S. (2019) Incorporating multi-criteria decision-making and fuzzy-value functions for flood 404 susceptibility assessment, Geocarto International. DOI: 10.1080/10106049.2019.1695958 
415 Vol. 96, pp: 15-36.

416 Chung S.H., Lee A.H.L. and Pearn W.L. 2005. Analytic network process (ANP) approach for 417 product mix planning in semiconductor fabricator. International Journal of Production Economics 418 Vol. 96, pp: 15-36.

419 Connor, R.F., Hiroki, K. 2005. Development of a method for assessing flood vulnerability. Water 420 Science \& Technology, 51 (5): 61-67

421 Costache, R. and Bui, D.T., 2020. Identification of areas prone to flash-flood phenomena using 422 multiple-criteria decision-making, bivariate statistics, machine learning and their 423 ensembles. Science of The Total Environment, 712, p.136492.

424 Costache, R., Pham, Q.B., Sharifi, E., Linh, N.T.T., Abba, S.I., Vojtek, M., Vojteková, J., Nhi, 425 P.T.T. and Khoi, D.N., 2020. Flash-flood susceptibility assessment using multi-criteria decision 426 making and machine learning supported by remote sensing and gis techniques. Remote 427 Sensing, 12(1), p.106. 
428 Cutter S.L. (1996) Vulnerability to environmental hazards. Progress in Human Geography 20 (4), $429 \quad 529-539$.

430 Davvodi, A., 2009. On inconsistency of a pairwise comparison matrix. International Journal of 431 Industrial Mathematics, 1(4), pp.343-350.

432 de Brito, M.M., Evers, M. and Almoradie, A.D.S., 2018. Participatory flood vulnerability 433 assessment: a multi-criteria approach. Hydrology \& Earth System Sciences, 22(1).

434 de Brito, M.M., Evers, M. and Höllermann, B., 2017. Prioritization of flood vulnerability, coping 435 capacity and exposure indicators through the Delphi technique: a case study in Taquari-Antas 436 basin, Brazil. International journal of disaster risk reduction, 24, pp.119-128.

437 Demir, V. and Kisi, O., 2016. Flood hazard mapping by using geographic information system and 438 hydraulic model: Mert River, Samsun, Turkey. Advances in Meteorology, 2016.

439 El-Haddad, B.A., Youssef, A.M., Pourghasemi, H.R., Pradhan, B., El-Shater, A.H. and El440 Khashab, M.H., 2020. Flood susceptibility prediction using four machine learning techniques and 441 comparison of their performance at Wadi Qena Basin, Egypt. Natural Hazards, pp.1-32.

442 Fekete, A., 2009. Validation of a social vulnerability index in context to river-floods in Germany. 443 Natural Hazards \& Earth System Sciences, 9(2).

444 Field, C.B., Barros, V.R., Mach, K., Mastrandrea M. 2014. Climate change 2014-Impacts, 445 adaptation and vulnerability: Regional aspects. Cambridge University Press. Contrib Work Gr II 446 to fifth Assess Rep Intergov panel Clim Chang.

447 Gabus A, Fontela E. 1972. World problems, an invitation to further thought within the framework 448 of DEMATEL. Geneva, Switzerland: Battelle Geneva Research Center, 1-8. 
449 Geravand, F., Hosseini, S.M. and Ataie-Ashtiani, B., 2020. Influence of river cross-section data 450 resolution on flood inundation modeling: Case study of Kashkan river basin in western Iran. 451 Journal of Hydrology, 584, p.124743.

452 Getahun, Y.S. and Gebre, S.L., 2015. Flood hazard assessment and mapping of flood inundation 453 area of the Awash River basin in Ethiopia using GIS and HEC-GeoRAS/HEC-RAS model. Journal 454 of Civil \& Environmental Engineering, 5(4), p.1.

455 Guo E.L., Zhang Z.Q. and Ren X.H., et al. 2014. Integrated risk assessment of flood disaster based 456 on improved set pair analysis and the variable fuzzy set theory in central Liaoning Province, 457 China.Nat. Hazards Journal, 74:947-965.

458 Hong, H.; Tsangaratos, P.; Ilia, I.; Liu, J.; Zhu, A.-X.; Chen, W. Application of fuzzy weight of 459 evidence and data mining techniques in construction of flood susceptibility map of Poyang County, 460 China. Sci. Total Environ. 2018, 625, 575-588.

461 Hosseini, F.S., Choubin, B., Mosavi, A., Nabipour, N., Shamshirband, S., Darabi, H. and 462 Haghighi, A.T., 2020. Flash-flood hazard assessment using ensembles and Bayesian-based 463 machine learning models: application of the simulated annealing feature selection method. Science 464 of the total environment, 711, p.135161.

465 Islam, A.R.M.T., Talukdar, S., Mahato, S., Kundu, S., Eibek, K.U., Pham, Q.B., Kuriqi, A. and 466 Linh, N.T.T., 2020. Flood susceptibility modelling using advanced ensemble machine learning 467 models. Geoscience Frontiers.

468 Jabbari, A.; Bae, D.-H. Application of Artificial Neural Networks for Accuracy Enhancements of 469 Real-Time Flood Forecasting in the Imjin Basin. Water 2018, 10, 1626.

470 JAMAB, 1999. Comprehensive Assessment of National Water Resources: Karkheh River Basin. 471 JAMAB Consulting Engineers in Association with Ministry of Energy, Iran. 
472 Karmaoui, A., S. F. Balica, and M. Messouli. 2016. "Analysis of applicability of flood 473 vulnerability index in Pre-Saharan region, a pilot study to assess flood in Southern Morocco." Nat.

474 Hazards Earth Syst. Sci. Discuss. 2: 1-24.

475 Kellens, W., Zaalberg, R., Neutens, T., Vanneuville, W. and De Maeyer, P., 2011. An analysis of 476 the public perception of flood risk on the Belgian coast. Risk Analysis: An International 477 Journal, 31(7), pp.1055-1068.

478 Khadivi M.R. and FatemGhomi S.M.T. (2012) Solid waste facilities location using of analytical 479 network process and data envelopment analysis approaches. Waste Management 32: 1258-1265. 480 Khosravi, K.; Pham, B.T.; Chapi, K.; Shirzadi, A.; Shahabi, H.; Revhaug, I.; Prakash, I.; Bui, D.T. 481 A comparative assessment of decision trees algorithms for flash flood susceptibility modeling at 482 Haraz watershed, northern Iran. Sci. Total Environ. 2018, 627, 744-755.

483 Kumar, D., Bhattacharjya, R.K. 2020. Estimation of Integrated Flood Vulnerability Index for the 484 Hilly

485 Lee, G., Jun, K.S. and Chung, E.S., 2013. Integrated multi-criteria flood vulnerability approach 486 using fuzzy TOPSIS and Delphi technique. Natural Hazards and Earth System Sciences, 13(5), 487 p.1293.

488 Lim, J.; Lee, K.-S. Flood Mapping Using Multi-Source Remotely Sensed Data and Logistic 489 Regression in the Heterogeneous Mountainous Regions in North Korea. Remote Sens. 2018, 10, 4901036.

491 Lin, C. T., Lee, C., \& Wu, C. S. (2009). Optimizing a marketing expert decision process for the 492 private hotel. Expert Systems with Applications, 36, 5613-5619. 493 https://doi.org/10.1016/j.eswa.2008.06.113 
494 Liu, J.; Xu, Z.; Chen, F.; Chen, F.; Zhang, L. Flood Hazard Mapping and Assessment on the 495 Angkor World Heritage Site, Cambodia. Remote Sens. 2019, 11, 98.

496 Luu, C.; von Meding, J. A Flood Risk Assessment of Quang Nam, Vietnam Using Spatial 497 Multicriteria Decision Analysis. Water 2018, 10, 461.

498 Modarres, R., Sarhadi, A. and Burn, D.H., 2016. Changes of extreme drought and flood events in 499 Iran. Global and Planetary Change, 144, pp.67-81.

500 Nachappa, T.G., Piralilou, S.T., Gholamnia, K., Ghorbanzadeh, O., Rahmati, O. and Blaschke, T., 501 2020. Flood susceptibility mapping with machine learning, multi-criteria decision analysis and 502 ensemble using Dempster Shafer Theory. Journal of Hydrology, p.125275.

503 National Statistics Center of Iran. 2016. General Population and Housing Census and Agricultural 504 Census. https://www.amar.org.ir/

505 Ouma, Y.O. and Tateishi, R., 2014. Urban flood vulnerability and risk mapping using integrated 506 multi-parametric AHP and GIS: methodological overview and case study assessment. Water, 6(6), 507 pp.1515-1545.

508 Ouma, Y.O. and Tateishi, R., 2014. Urban flood vulnerability and risk mapping using integrated 509 multi-parametric AHP and GIS: methodological overview and case study assessment. Water, 6(6), $510 \quad$ pp.1515-1545.

511 Ozdemir, M.S., 2005. Validity and inconsistency in the analytic hierarchy process. Applied 512 Mathematics and Computation, 161(3), pp.707-720.

513 Patial, J.P, Savangi, a, Singh, O.P, Singh, A.K, Ahmad, T. 2008. Development of a GIS Interface 514 for estimation of Runoff from Watersheds Water Resources Management, 22, 221, 1239

515 Petit-Boix, A., Sevigne-Itoiz, E., Rojas-Gutierrez, L.A., Barbassa, A.P., Josa, A., Rieradevall, J., 516 Gabarrell, X., 2017. Floods and consequential life cycle assessment: integrating flood damage into 
517 the environmental assessment of stormwater Best Management Practices. J. Cleaner Prod. 162, $518 \quad 601-608$.

519 Region of Uttarakhand, India. J. Hazard. Toxic Radioact. Waste, 24(4): 04020051

520 Saaty, T.L., 2001. Decision making with the analytic network process (ANP) and its super 521 decisions software: The national missile defense (NMD) example. ISAHP 2001 proceedings, pp.25224.

523 Saaty, T.L., 2005. Theory and applications of the analytic network process: decision making with 524 benefits, opportunities, costs, and risks. RWS Publications, Pittsburgh, PA 4922 Ellsworth 525 Avenue, Pittsburgh, PA 15213.

526 Sadeghi-Pouya, A., J. Nouri, N. Mansouri, and A. Kia-Lashaki. 2017. "An indexing approach to 527 assess flood vulnerability in the western coastal cities of Mazandaran, Iran.” Int. J. Disaster Risk 528 Reduct. 22: 304-316.

529 Sahoo, S., Dhar, A., \& Kar, A. 2016. Environmental vulnerability assessment using Grey Analytic 530 Hierarchy Process based model. Environmental Impact Assessment Review, 56, 145-154.

531 Sajedi-Hosseini, F., Choubin, B., Solaimani, K., Cerdà, A., \& Kavian, A. (2018). Spatial prediction 532 of soil erosion susceptibility using FANP: Application of the Fuzzy DEMATEL approach. Land 533 Degradation \& Development. DOI: 10.1002/ldr.3058 .

534 Samanlioglu, F., \& Aya, Z. (2016). Fuzzy ANP-based PROMETHEE II approach for evaluation 535 of machine tool alternatives. Journal of Intelligent Fuzzy Systems, 30, 2223-2235 .

536 Tang, X., Li, J., Liu, M., Liu, W. and Hong, H., 2020. Flood susceptibility assessment based on a 537 novel random Naïve Bayes method: A comparison between different factor discretization 538 methods. Catena, 190, p.104536. 
539 Tehrany, M.S.; Lee, M.-J.; Pradhan, B.; Jebur, M.N.; Lee, S. Flood susceptibility mapping using

540 integrated bivariate and multivariate statistical models. Environ. Earth Sci. 2014, 72, 4001-4015.

541 Tehrany, M.S.; Pradhan, B.; Jebur, M.N. Flood susceptibility analysis and its verification using a

542 novel ensemble support vector machine and frequency ratio method. Stoch. Environ. Res. Risk

543 Assess. 2015, 29, 1149-1165.

544 Termeh, S.V.R.; Kornejady, A.; Pourghasemi, H.R.; Keesstra, S. Flood susceptibility mapping 545 using novel ensembles of adaptive neuro fuzzy inference system and metaheuristic algorithms.

546 Sci. Total Environ. 2018, 615, 438-451.

547 Tummala, V.R. and Wan, Y.W., 1994. On the mean random inconsistency index of analytic 548 hierarchy process (AHP). Computers \& industrial engineering, 27(1-4), pp.401-404.

549 United Nations International Strategy for Disaster Reduction (UNISDR). 2009. Making Disaster 550 Risk Reduction Gender Sensitive: Policy and Practical Guidelines. 551 http://repo.floodalliance.net/jspui/44111/1124

552 Yang, W., Xu, K., Lian, J., Ma, C. and Bin, L., 2018. Integrated flood vulnerability assessment 553 approach based on TOPSIS and Shannon entropy methods. Ecological Indicators, 89, pp.269-280. 
Figures
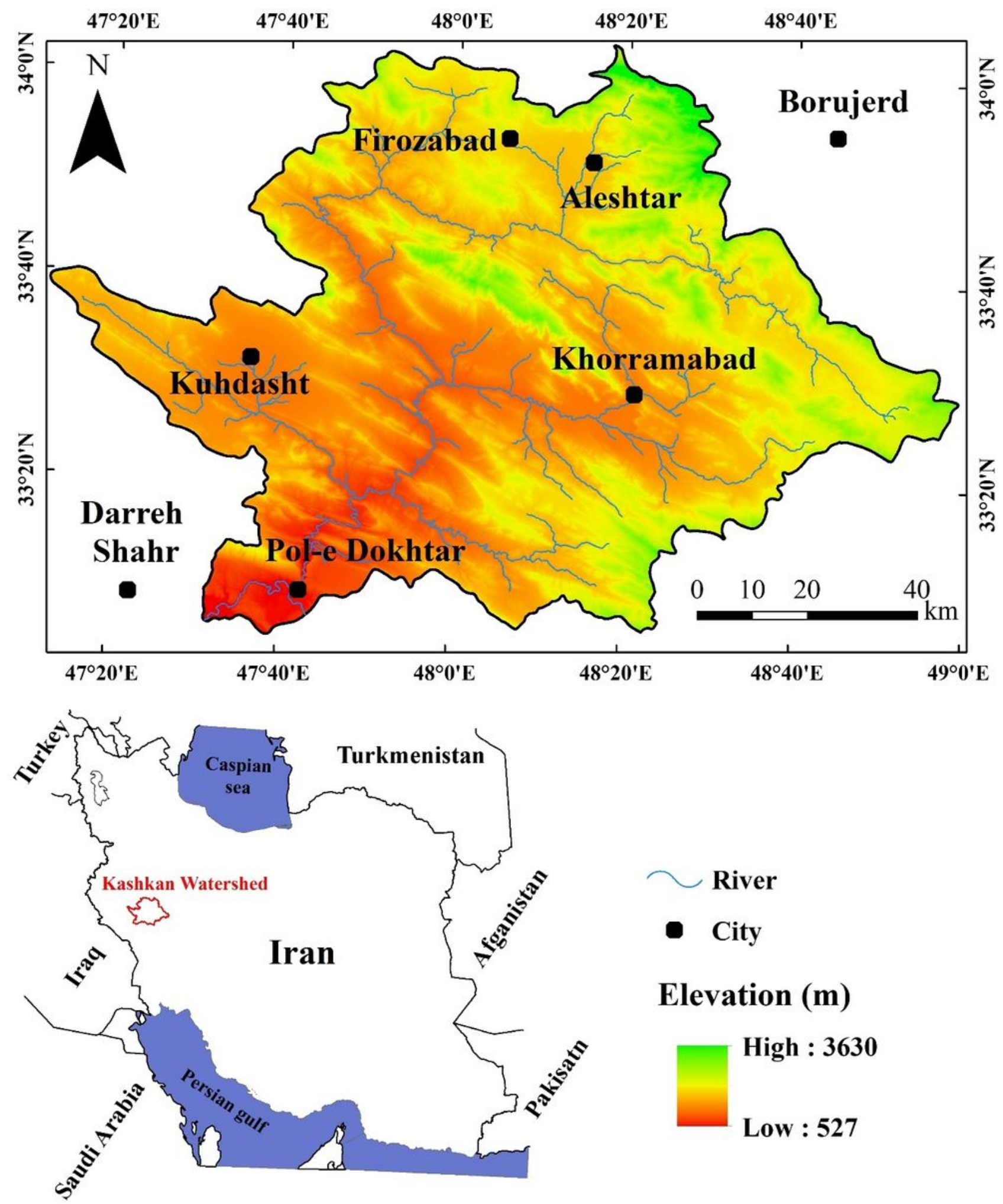

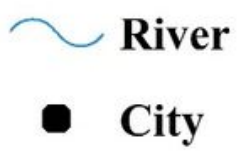

Elevation (m)

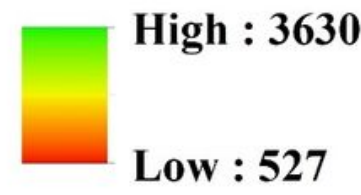

Figure 1

Location of the study area Note: The designations employed and the presentation of the material on this map do not imply the expression of any opinion whatsoever on the part of Research Square concerning 
the legal status of any country, territory, city or area or of its authorities, or concerning the delimitation of its frontiers or boundaries. This map has been provided by the authors.
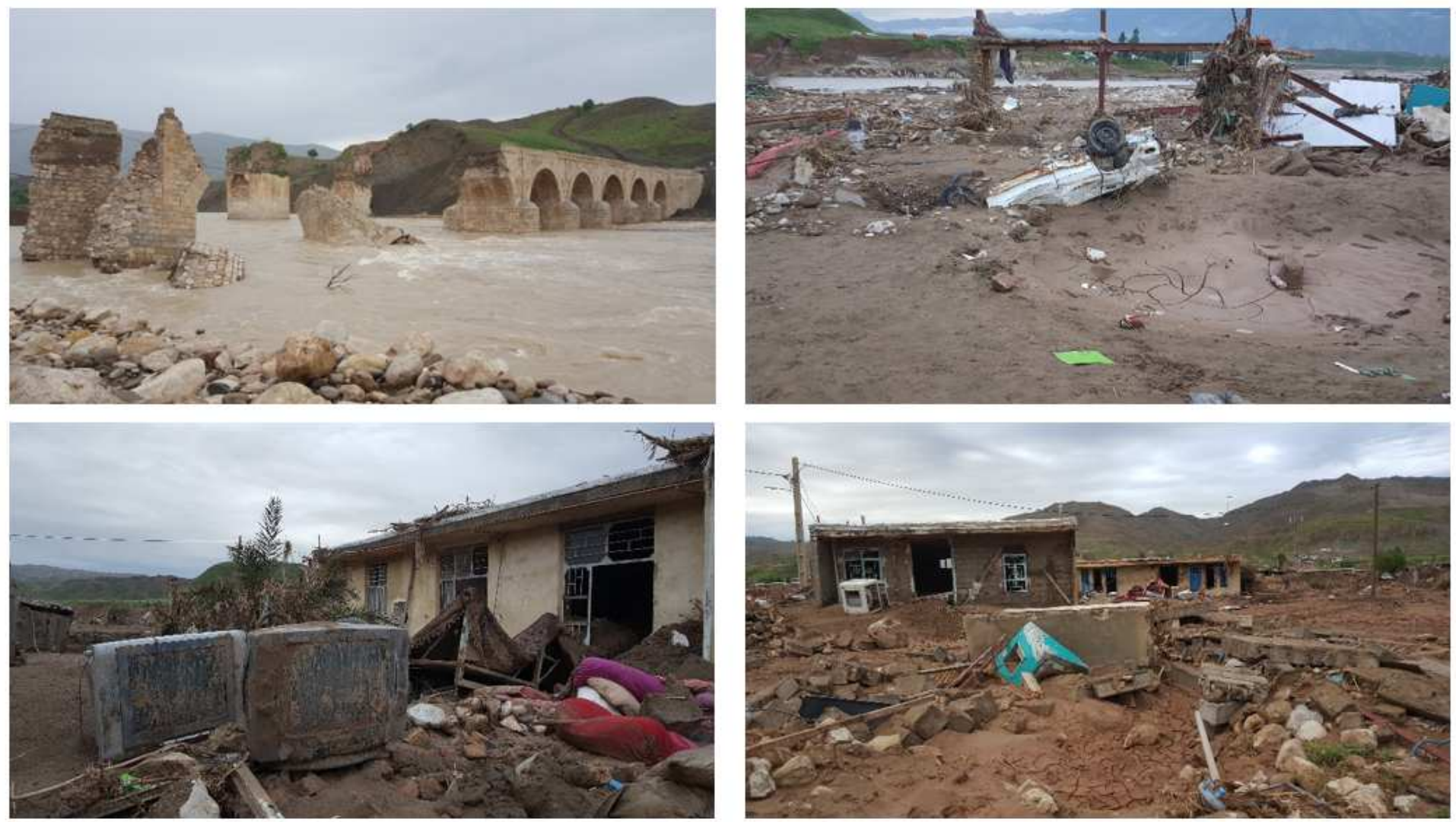

Figure 2

Some photos of the flood damage in March 2019. Photos were taken by Shahram Khalighi Sigaroodi. 


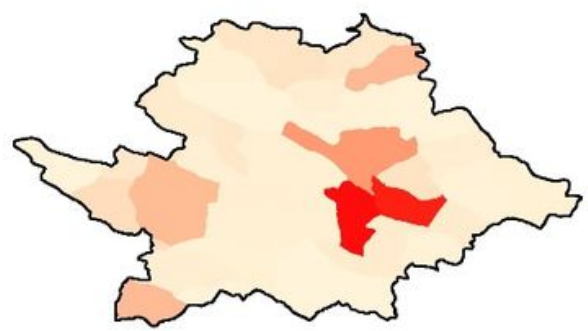

(a) $\mathrm{PD}\left(\mathrm{n} / \mathrm{km}^{2}\right)$

High : 590

Low : 6

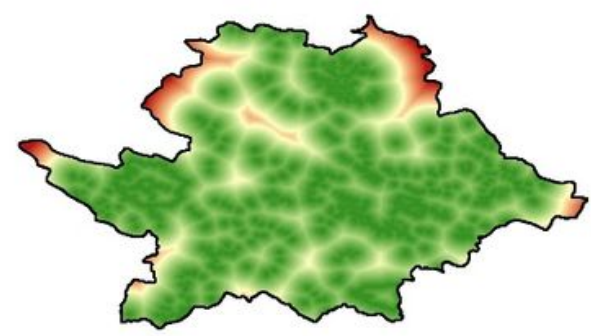

(d) DTIM (m)

High : 18960

Low : 0

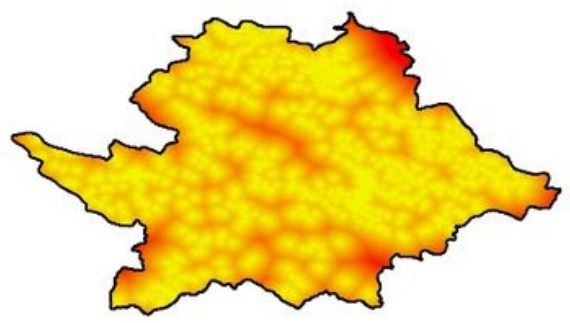

(g) DTRe (m)

High : 18150

Low : 0

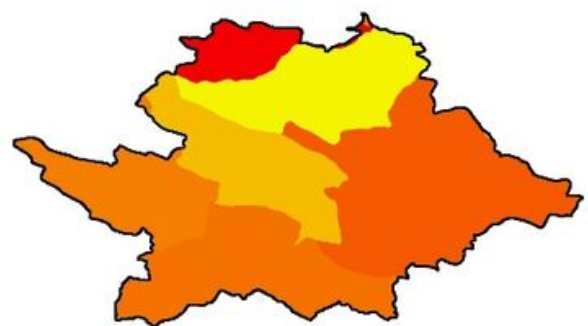

(b) $\mathbf{L D}\left(\mathrm{n} / \mathrm{km}^{2}\right)$

High : 81

Low : 5

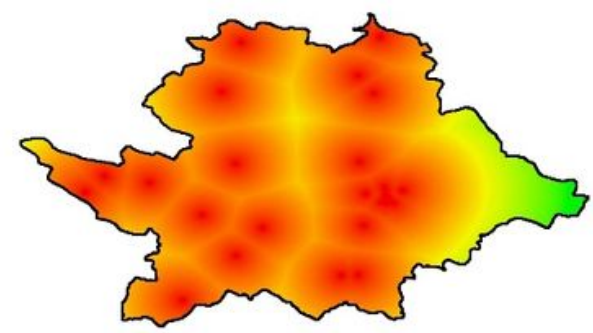

(e) DTTCH (m)

High : 54500

Low : 0

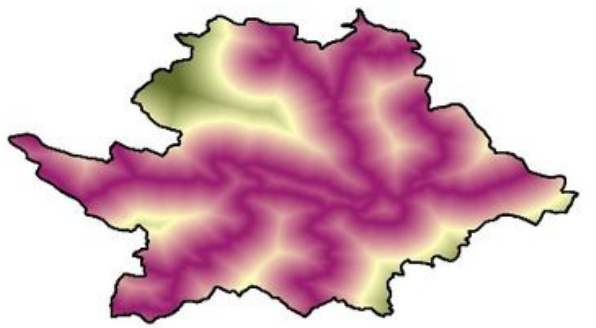

(h) DTR (m)

High : 29780

Low : 0

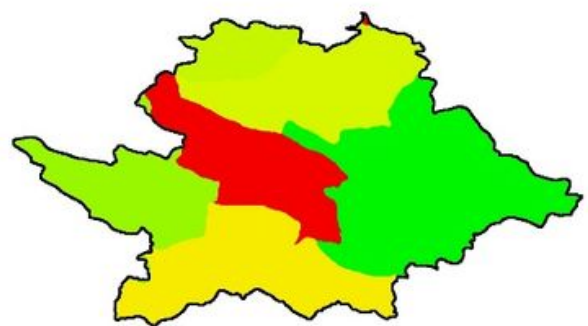

(c) PFR (\%)

High : 46

Low : 8

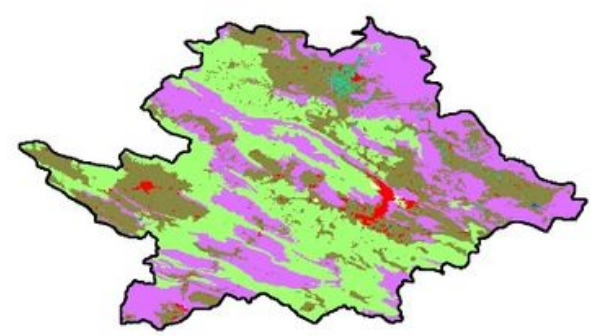

(f) Landuse

Agriculture

Forest

Orchard

Rangeland

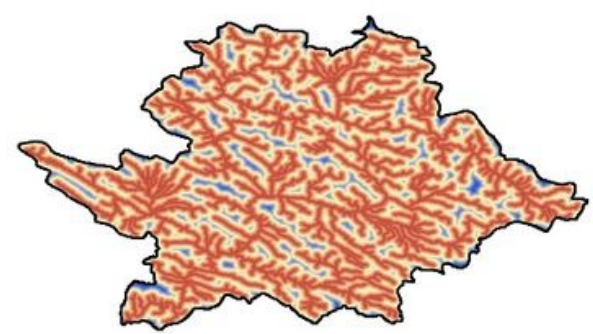

(i) DTS (m)

High : 6815

Low : 0
Residential

Barren land

Waterbody

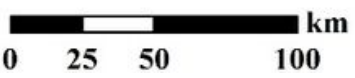

i

\section{Figure 3}

Flood vulnerability variables: (a) population density (PD), (b) livestock density (LD), (c) percentage of farmers and ranchers (PFR), (d) distance to industrial and mining areas (DTIM), (e) distance to tourist and cultural heritage areas (DTTCH), (f) land use, (g) distance to residential areas (DTRe), (h) distance to road (DTR), and (i) distance to stream (DTS). Note: The designations employed and the presentation of the material on this map do not imply the expression of any opinion whatsoever on the part of Research 
Square concerning the legal status of any country, territory, city or area or of its authorities, or concerning the delimitation of its frontiers or boundaries. This map has been provided by the authors.

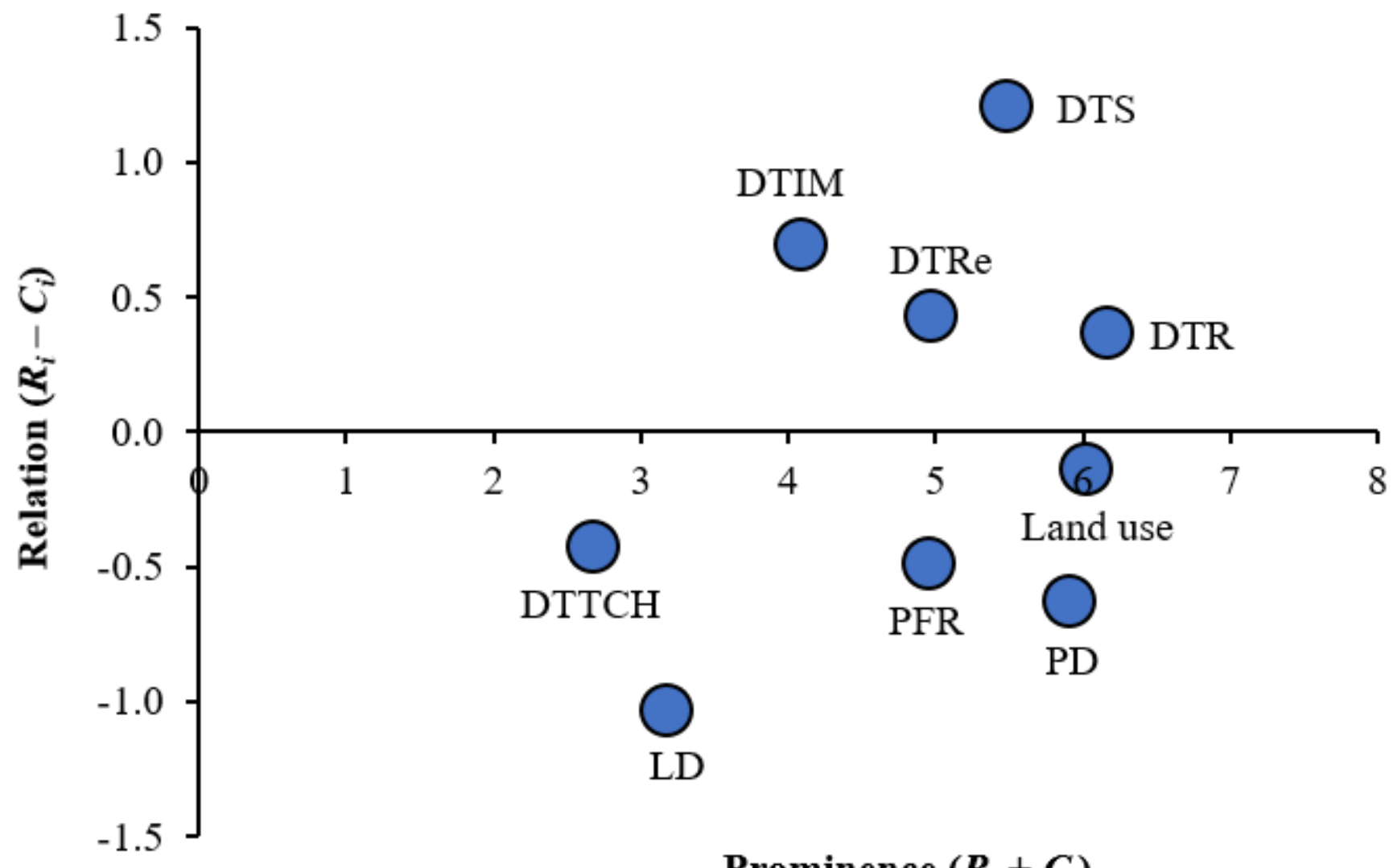

Figure 4

Causal diagram representing the relation (cause/effect) and prominence (interaction) of the variables in the whole network. 


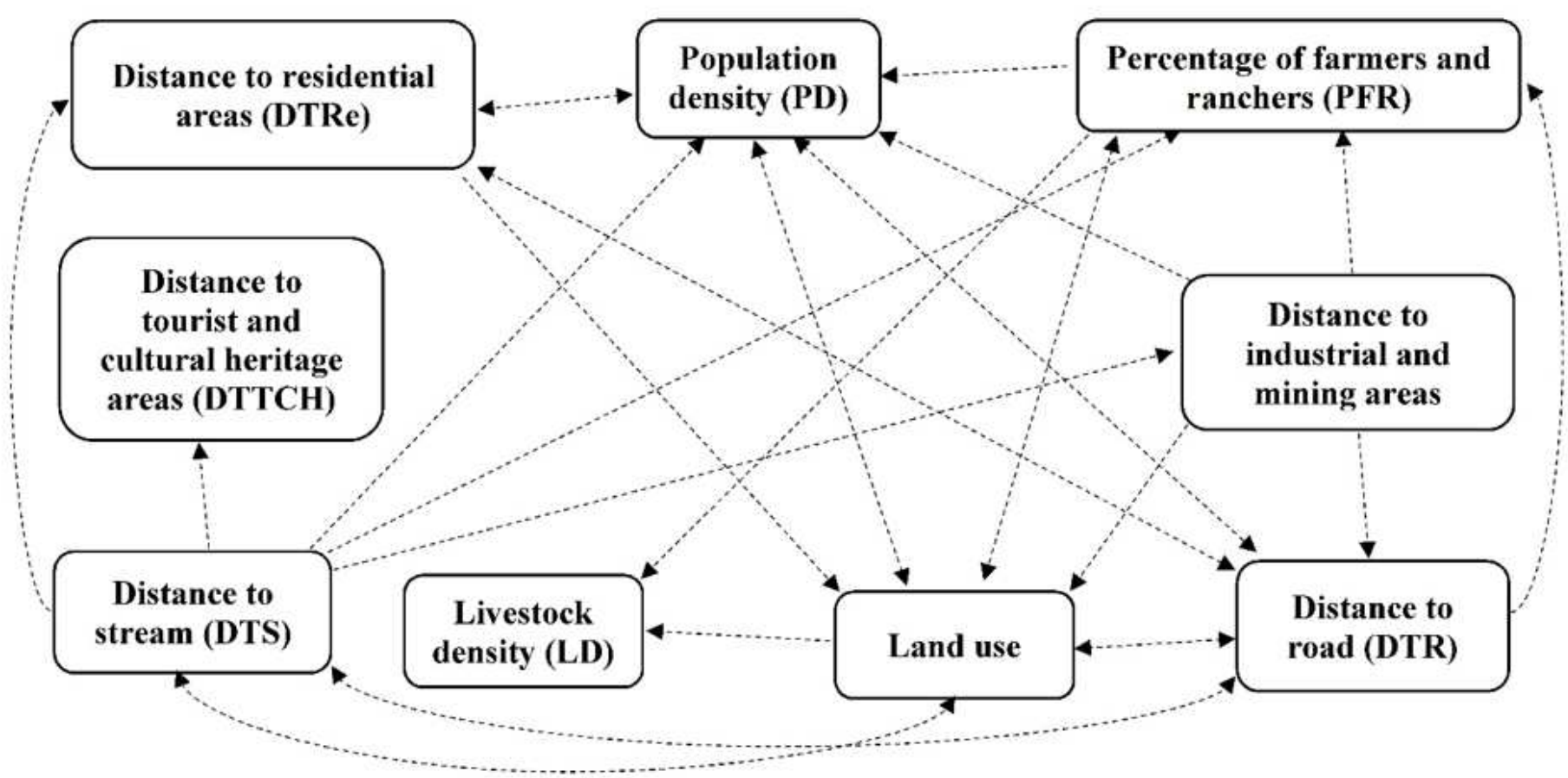

Figure 5

Designed network structure among the flood vulnerability variables by the DEMATEL method 

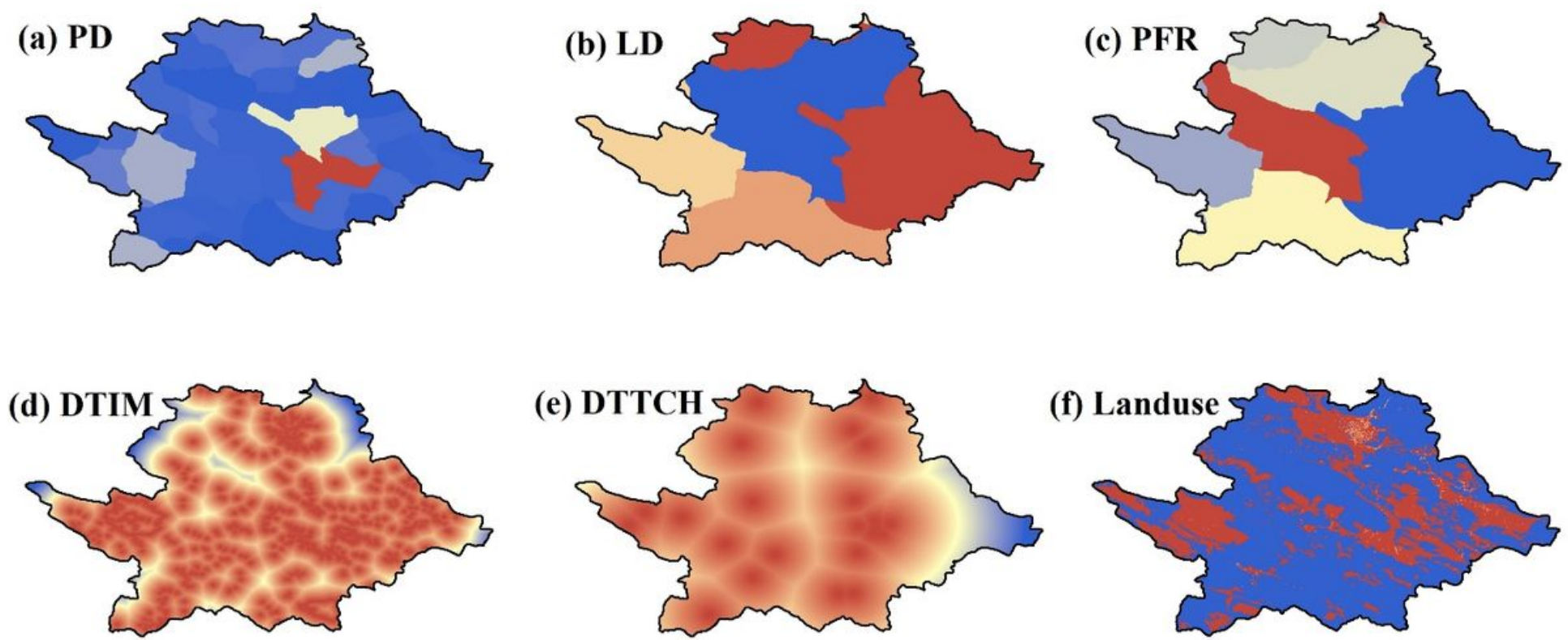

(e)
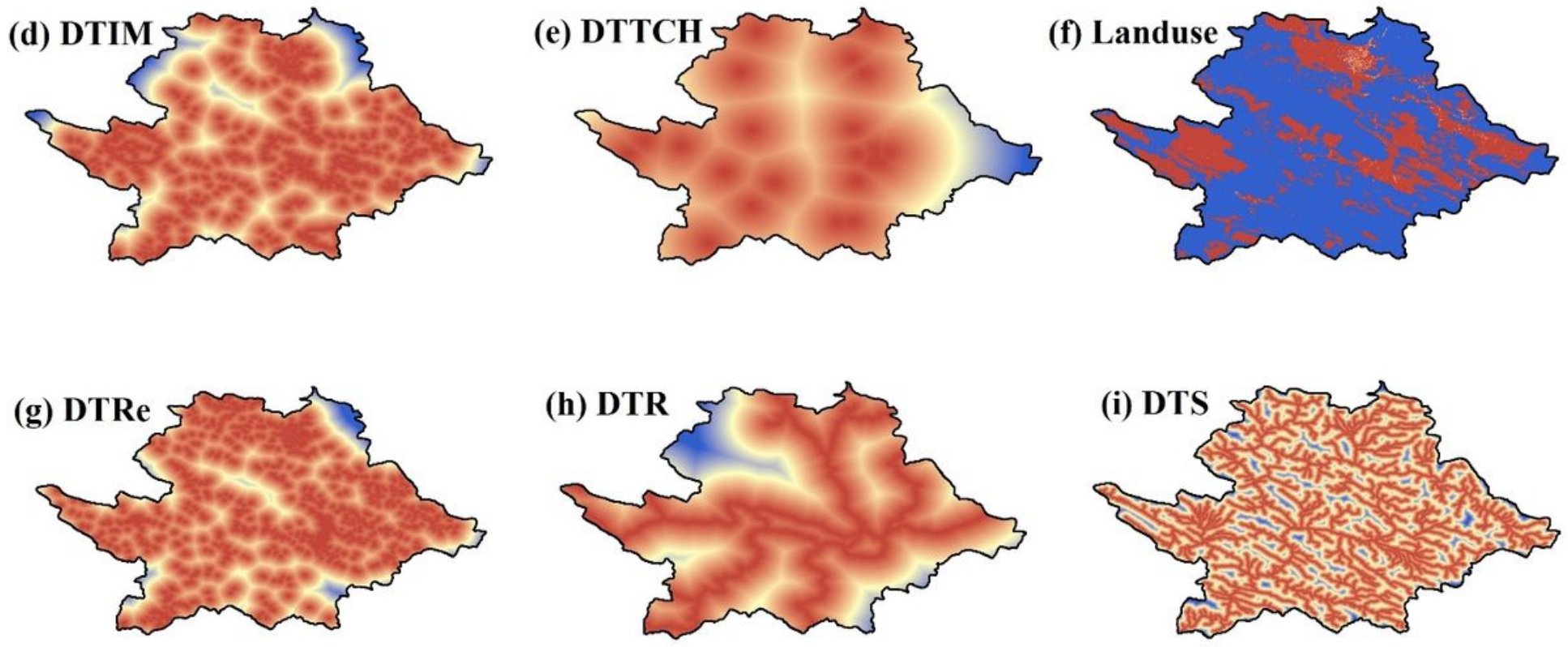

\section{Normalized flood vulnerability factors}

\section{High : 1}

Low : 0

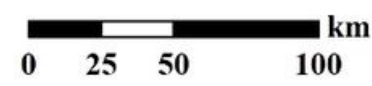

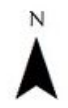

Figure 6

Normalized flood vulnerability factors: (a) population density (PD), (b) livestock density (LD), (c) percentage of farmers and ranchers (PFR), (d) distance to industrial and mining areas (DTIM), (e) distance to tourist and cultural heritage areas (DTTCH), (f) land use, (g) distance to residential areas (DTRe), (h) distance to road (DTR), and (i) distance to stream (DTS). Note: The designations employed and the presentation of the material on this map do not imply the expression of any opinion whatsoever on the part of Research Square concerning the legal status of any country, territory, city or area or of its authorities, or concerning the delimitation of its frontiers or boundaries. This map has been provided by the authors. 


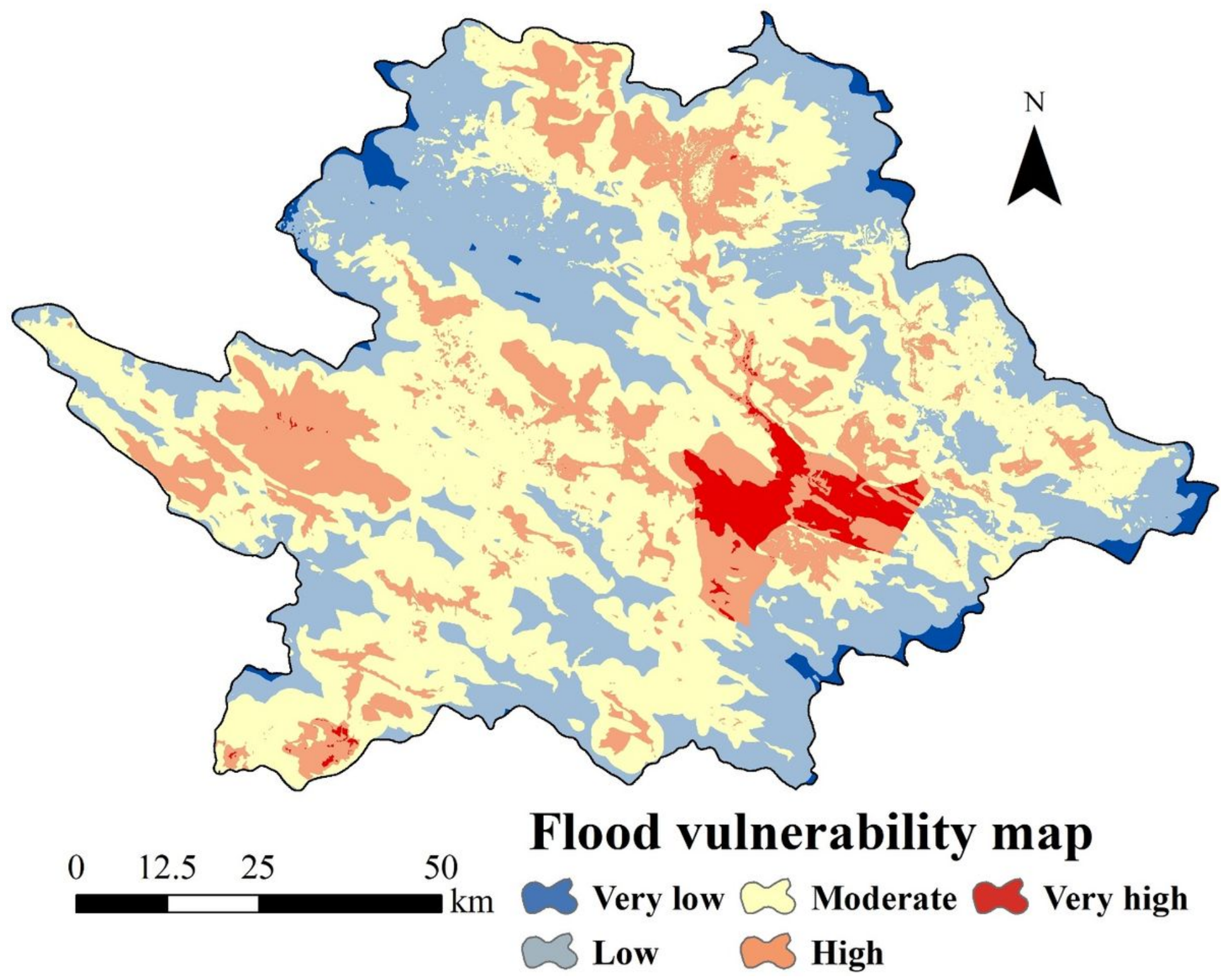

Figure 7

Flood vulnerability map in the Kashkan watershed. Note: The designations employed and the presentation of the material on this map do not imply the expression of any opinion whatsoever on the part of Research Square concerning the legal status of any country, territory, city or area or of its authorities, or concerning the delimitation of its frontiers or boundaries. This map has been provided by the authors. 